Illinois State University

ISU ReD: Research and eData

Theses and Dissertations

9-17-2016

\title{
The Effects Of Cultural Cognition And Parent Perceptions Of Autism Spectrum Disorder On Perceptions Of Intervention Efficacy
}

Jillian R. Reiher

Illinois State University, jreiher@ilstu.edu

Follow this and additional works at: https://ir.library.illinoisstate.edu/etd

Part of the Psychology Commons

\section{Recommended Citation}

Reiher, Jillian R., "The Effects Of Cultural Cognition And Parent Perceptions Of Autism Spectrum Disorder On Perceptions Of Intervention Efficacy" (2016). Theses and Dissertations. 629.

https://ir.library.illinoisstate.edu/etd/629

This Thesis is brought to you for free and open access by ISU ReD: Research and eData. It has been accepted for inclusion in Theses and Dissertations by an authorized administrator of ISU ReD: Research and eData. For more information, please contact ISUReD@ilstu.edu. 


\title{
THE EFFECTS OF CULTURAL COGNITION AND PARENT PERCEPTIONS OF AUTISM SPECTRUM DISORDER ON PERCEPTIONS OF INTERVENTION EFFICACY
}

\author{
Jillian R. Reiher
}

\section{Pages}

Previous research has identified many interventions for Autism Spectrum Disorders (ASD). Some of these interventions are evidence-based; others are not. However, previous research has also found that parents select interventions for their children with ASD on the basis of several factors other than the evidence base, including their emotional representations of ASD and their perceptions of the timeline, consequences, and causes of ASD. Other research has found that people's cultural worldviews influence their decision-making on a variety of social and political issues. The current study examined the relationships between these factors and parents' perceptions of the efficacy of evidence-based and non-evidence-based interventions. Contrary to previous research, for parents of children with ASD, perceptions of intervention efficacy were not affected by their emotional representations of ASD or their perceptions of the timeline or consequences of ASD. There was a relationship between parents' perceptions of the causes of ASD and their perceptions of the efficacy of some interventions. Parents' cultural worldview was not related to their perceptions of the 
efficacy of evidence-based interventions, but was related to their perceptions of nonevidence-based interventions. Further research is needed to determine other factors that influence how parents perceive ASD interventions.

KEYWORDS: Autism Spectrum Disorders, Interventions, Cultural Worldview, Efficacy 
THE EFFECTS OF CULTURAL COGNITION AND PARENT

PERCEPTIONS OF AUTISM SPECTRUM DISORDER

ON PERCEPTIONS OF INTERVENTION EFFICACY

JILLIAN R. REIHER

A Thesis Submitted in Partial Fulfillment of the Requirements for the Degree of

MASTER OF SCIENCE

Department of Psychology

ILLINOIS STATE UNIVERSITY

2016 
(C) 2016 Jillian R. Reiher 
THE EFFECTS OF CULTURAL COGNITION AND PARENT

PERCEPTIONS OF AUTISM SPECTRUM DISORDER

ON PERCEPTIONS OF INTERVENTION EFFICACY

JILLIAN R. REIHER

COMMITTEE MEMBERS:

Corinne Zimmerman, Chair

Marla Reese-Weber 


\section{ACKNOWLEDGMENTS}

I would like to thank my committee members, Corinne Zimmerman and Marla Reese-Weber for their guidance and support on this project. I would also like to thank Steve Croker for helping me get my project started and for his assistance with my initial

data analysis. Additionally, I would like to thank Emilio Lobato for answering my many, many questions about Select Survey and regression. I also thank Karla Doepke for helping recruit parents of children with autism spectrum disorder. Aside from the wonderful people listed above, I also need to thank my amazing cohort members, family, and friends being a source of support throughout the entire process.

J. R. R. 
CONTENTS

Page

ACKNOWLEDGMENTS

i

CONTENTS

TABLES $\quad$ iv

FIGURES

CHAPTER

I. THE PROBLEM AND ITS BACKGROUND 1

Statement of the Problem 1

II. REVIEW OF THE LITERATURE 3

Autism Spectrum Disorder 3

Evidence-Based Reasoning About Health Issues $\quad 5$

Parental Decision-Making About ASD Interventions $\quad 8$

Therapeutic Approaches to ASD 13

Evidence-Based Interventions 14

Interventions With Insufficient Evidence $\quad 14$

$\begin{array}{ll}\text { Ineffective Interventions } & 18\end{array}$

Cultural Cognition 18

Research Questions and Hypotheses 23

Illness Perceptions $\quad 25$

Cultural Cognition $\quad 27$

Predictors of Intervention Efficacy by Parents of Children With ASD 30

Differences Between Parent Groups $\quad 30$

Exploratory Research Questions 31

III. METHOD 33 
$\begin{array}{ll}\text { Participants } & 33\end{array}$

$\begin{array}{ll}\text { Measures } & 34\end{array}$

Illness Perception Questionnaire-Revised for Autism, English Version (IPQ-RAE)

Illness Perception Questionnaire for Healthy PeopleRevised for Autism, English Version (IPQ-RAEH) 36

Specific Therapeutic Approaches Rating System-Child Form-ASD Subscale-Revised (STARS-CFA-R) 36 Cultural Cognition $\quad 38$

$\begin{array}{ll}\text { Procedure } & 38\end{array}$

IV. RESULTS 41

Descriptive Statistics 41

Exploratory Factor Analysis $\quad 43$

Tests of Hypotheses 43

Exploratory Research Questions 49

$\begin{array}{lll}\text { V. DISCUSSION } & 51\end{array}$

General Discussion $\quad 51$

$\begin{array}{ll}\text { Strengths and Limitations of the Current Study } & 57\end{array}$

Directions for Future Research $\quad 59$

Conclusions $\quad 60$

$\begin{array}{ll}\text { REFERENCES } & 61\end{array}$ 


\section{TABLES}

Table Page

1. Predicted Results for Hypothesis $1 \quad 64$

2. Predicted Results for Hypothesis $2 \quad 65$

3. IPQ and IPQ-P Subscale Means and Standard Deviations 66

4. STARS and STARS-P Perceived Intervention Efficacy 67

5. Cultural Worldview Subscale Means and Standard Deviations 69

6. Actual Results for Hypothesis $1 \quad 70$

$\begin{array}{lll}\text { 7. Actual Results for Hypothesis } 2 & 71\end{array}$

8. Summary of Hierarchical Regression Analysis for Variables Predicting Perceived Efficacy of ABA and PRT for Parents of Children With ASD 72

9. Summary of Hierarchical Regression Analysis for Variables Predicting Perceived Efficacy of ABA and PRT for Parents of Children With and Without ASD

10. Summary of Hierarchical Regression Analysis for Variables Predicting Perceived Efficacy Factor Analysis Alternative Interventions for Parents of Children With and Without ASD

11. Summary of Hierarchical Regression Analysis for Variables Predicting Perceived Efficacy of NAC Unestablished Interventions for Parents of Children With and Without ASD 


\section{FIGURES}

Figure $\quad$ Page

1. The Two Dimensions of Cultural Cognition According to Kahan (2010) 19

2. The Predicted Relationship Between Mean Perceived Efficacy of ABA and PRT and the H-E Subscale of the Cultural Worldview Scales

3. The Predicted Relationship Between Perceived Efficacy of ABA and PRT and the I-C Subscale of the Cultural Worldview Scales

4. The Predicted Relationship Between Mean Perceived Efficacy of Non-Evidence-Based Interventions and the H-E Subscale of the Cultural Worldview Scales

5. The Predicted Relationship Between Mean Perceived Efficacy of Non-Evidence-Based Interventions and the I-C Subscale of the Cultural Worldview Scales 


\section{CHAPTER I}

\section{THE PROBLEM AND ITS BACKGROUND}

\section{Statement of the Problem}

Parents of children with Autism Spectrum Disorder (ASD) are faced with a wide variety of interventions when selecting appropriate treatments for their children. The evidence base for these interventions ranges from strong to nonexistent (Green et al., 2006). Although effective communication of the evidence base for interventions might help parents make their decision, parents' values, and well as individual child and parent factors, also play a role in the decision-making process (Bruine de Bruin \& Bostrom, 2013; Fischhoff \& Davis, 2014). The decisions parents make about their children's interventions could be influenced by their perceptions of ASD and its causes. Parents' ratings of the seriousness, timeline, and cause of ASD have all been found to be related to interventions selected, as has parents' affect toward ASD (Al Anbar, Dardennes, PradoNetto, Kaye, \& Contejean, 2010).

As previously mentioned, values can affect people's evaluation of scientific information. One method of assessing these values and their influence on decisionmaking is to consider the role of cultural cognition (Kahan, Braman, \& Jenkins-Smith, 2011). According to the cultural cognition thesis, people's perceptions of facts are affected by their values, such that people view actions that fit with their values as 
desirable, and those that do not as non-desirable. Cultural cognition, in the work of Kahan and colleagues (Kahan, 2010; Kahan et al., 2011; Kahan, Bramam, Slovic, Gastil, \& Cohen, 2008; Kahan, Hoffman, Braman, Evans, \& Rachlinksi, 2012) is measured by where people fall on two intersecting dimensions: hierarchy-egalitarianism and individualism-communitarianism.

In the current study, I examine how parents' perceptions of the efficacy of ASD interventions are affected by their perceptions of ASD and their cultural worldview. Additionally, I compare the perceptions of parents whose children have ASD and those whose children do not have ASD. In my review of the literature, I first describe ASD, including its defining features, prognosis, and prevalence. I then discuss factors related to decision-making about health issues, including ASD. Next, I review the evidence base for some ASD interventions. Finally, I discuss Kahan's work on cultural cognition, including how it is assessed. 


\section{CHAPTER II}

\section{REVIEW OF THE LITERATURE \\ Autism Spectrum Disorder}

Autism Spectrum Disorder (ASD) includes diagnoses previously labeled as autism, Asperger's, childhood disintegrative disorder, Rhett's, and pervasive developmental disorder not otherwise specified (PDD-NOS). ASD is associated with social communication and interaction difficulties and restricted or repetitive patterns of behavior or interest. Additionally, these difficulties must have been present since early childhood and must cause a clinically significant disturbance in the child's life. Intellectual disability can co-occur with ASD, but it is not a diagnostic feature. Delays in learning language are also common. Additionally, other conditions such as Down Syndrome, epilepsy, and attention-deficit/hyperactivity disorder can co-occur with ASD (American Psychiatric Association, 2013).

The severity of ASD varies widely across diagnosed individuals. Some individuals diagnosed with ASD are able to live with minimal support, while others require life-long intensive care. According to the Diagnostic and Statistical Manual of Mental Disorders ( $5^{\text {th }}$ ed.; DSM-5; American Psychiatric Association, 2013), examples of social communication deficits experienced by people whose ASD severity is classified as Level 1 include difficulties initiating social interactions and a lack of interest in social interactions. Level 1 restricted, repetitive behaviors include difficulty switching between 
activities and organizing one's time. People whose ASD severity is classified as Level 2 often only speak in short, simple sentences and have noticeable difficulties understanding and using nonverbal behaviors. They also engage in restricted or repetitive behaviors often enough to be noticed by casual observers. Individuals whose ASD severity is rated as Level 3 may not exhibit any verbal communication. They engage in repetitive or restricted behaviors to an extent that interferes with all aspects of their lives.

Additionally, people whose ASD severity is rated as Level 3 often demonstrate major distress when directed to change their actions (American Psychiatric Association, 2013).

Symptoms of ASD generally emerge when children are between 12 and 24 months old. Some children may experience a regression in skills around that time, especially in the area of communication. Most individuals with ASD improve their functioning through adolescence, although some deteriorate during adolescence. Although symptoms generally emerge during early childhood, they are not always recognized until later in life. This is especially likely to be the case if symptoms are mild (American Psychiatric Association, 2013).

Individuals with ASD often struggle to live independently and have difficulty finding work as adults. Generally, activities of daily living are difficult for people with ASD due to their rigidity and difficulty with social communication. Prognosis for individuals with ASD is better if they do not have an intellectual disability, and if they exhibit functional language by around age five. ASD occurs across cultures, although age of diagnosis may be affected by socioeconomic or cultural factors (American Psychiatric Association, 2013). 
ASD currently affects approximately one in 68 children. It affects boys (one in 42) more often than girls (one in 189). Additionally, reported incidences of ASD have increased to their current rate from one in 150 since 2000 (CDC, 2014). However, as Taylor (2006) reports, it is unlikely that actual incidences of ASD have increased as dramatically. Instead, it is likely that the increase in the prevalence of ASD is mainly due to other factors such as the under-diagnosis of ASD in the past. Taylor specifically mentions the addition of ASD to the disability categories federally mandated to receive special education services as one reason why there might be an increase in reported incidences of autism. Additionally, ASD awareness has increased in both professionals and laypeople, leading to increases in parents seeking diagnoses and professionals making diagnoses.

Given the importance of early intervention for ASD, parents are required to make decisions about their children's treatment shortly after diagnosis. To understand how parents make these decisions, it is necessary to review the literature on scientific reasoning about health issues and factors that affect parents' decision making about ASD specifically. The scientific evidence base might play a role in the process, but other factors can also influence decision-making and how that evidence is perceived. These include cultural values and other parent and child influences.

\section{Evidence-Based Reasoning About Health Issues}

When selecting interventions for their children, parents of children with ASD have to process quite a bit of scientific information. As Fischhoff and Davis (2014) discuss, communicating scientific information to the public requires both the simplification of some scientific concepts, and the explanation of assumptions that 
scientists take for granted. For example, professionals who work with children with ASD from an Applied Behavior Analysis (ABA) perspective frequently use the terms "reinforcement" and "prompting." Within the professional community, the terms are well defined. Although they are commonly used within ABA, the terms were derived from fairly complex behavioral principles. When teaching $\mathrm{ABA}$ interventions to parents, professionals need to be able to define these terms without using complicated scientific language. Additionally, Fischhoff and Davis point out that scientific communication is driven by what laypeople need to know, rather than what scientists want to communicate. Effective communication of scientific information is an important component of influencing behavioral change (Bruine de Bruin \& Bostrom, 2013). Similar to Fischhoff and Davis (2014), Bruine de Bruin and Bostrom stress that scientists should keep in mind the public's needs when communicating scientific information. They state that experts often forget what it is like to be a novice, so they do not communicate the appropriate information.

Fischhoff and Davis (2014) also note that scientific decision-making involves values as well as facts. Von Winterfeldt (2013) supports a mathematical decision-making strategy that takes into account scientific facts and people's values. He gives an example of using this strategy with a power company and a group of homeowners. Some research had indicated that people living near power lines were at increased risk of health problems, including childhood leukemia. Homeowners wanted the power company to solve the problem by installing the power lines underground, but the power company did not believe it was necessary. A third solution was also proposed that involved mitigating the risk of the above ground power lines. After much analysis of the costs and benefits of 
all solutions, mitigating the risk of the current power lines was found to be the lowestcost, highest-benefit solution. Although the plan was never carried out because of a state energy crisis, von Winterfeldt mentions that neither group was happy with the solution determined to be the best by the analysis. They felt the analysis was accurate, but the solution proposed by it conflicted with their values. The costs, risks, and benefits of the situation von Winterfeldt describes were fairly straightforward. This is not always true of the evidence base for health-related interventions.

Because determining the evidence base for health-related interventions is complex, some research has indicated a need for actively debunking information about interventions that are not evidence-based in addition to providing information about those that are evidence-based. When studying a group of college students enrolled in a child psychology course, Hupp, Stary, Bradshaw, and Owens (2012) found that although students' endorsements of evidence-based treatments increased after taking the class, so did their endorsements of alternative treatments. The researchers created the Specific Therapeutic Approaches Rating Scale-Child Form (STARS-CF), which measured their participants' opinions of the effectiveness of autism, oppositional defiant disorder (ODD), attention deficit/hyperactivity disorder (ADHD), and depression interventions. The measure includes 13 evidence-based treatments and 23 alternative treatments. Students were given the measure at the beginning and end of the semester. Hupp et al. concluded that simply teaching students which interventions are evidence-based did not limit students' perceptions of the efficacy of alternative treatments. Instead, students' perceptions of the efficacy of facilitated communication, a non-empirically supported intervention for ASD, actually increased when measured at the end of the semester. Hupp 
et al. speculated that this might have occurred because teaching individuals with ASD to communicate was emphasized as an important intervention. Without specific knowledge about facilitated communication, students assumed that an intervention that focused on communication would be beneficial for children with ASD.

Another study by Hupp, McKenney, Schmittel, McCobin, and Owens, (2013)

replicated and extended the study by Hupp et al. (2012). The same rating scale procedure was used, but the class size was larger and students received explicit instruction on the lack of evidence base for eight of the 23 alternative treatments listed. As in the previous study, researchers found participants' perceived efficacy of evidence-based interventions increased after taking the class. During this study, they did find a significant decrease in participant's perceptions of the efficacy of the eight alternative treatments discussed in class. However, this decrease in perceived efficacy did not generalize to the 15 remaining treatments. From these findings, the researchers concluded that in addition to explicit teaching on types of treatments, students should receive training on evaluating the evidence base of interventions.

\section{Parental Decision-Making About ASD Interventions}

Students in the Hupp et al. (2012) study only had to rate whether 33 interventions were effective in treating children's mental and developmental disorders. Parents of children with ASD actually have a much wider array of interventions to choose from. Additionally, students in the Hupp et al. (2013) study received direct instruction on the evidence base for, or lack thereof, for 21 of the interventions (13 evidence-based and eight alternative). The information parents receive about the evidence base for interventions is rarely so straightforward. Parents have to choose from many 
interventions, and although some of the information they encounter is scientifically supported, other information is not. When evaluating an intervention, parents have to evaluate both its source and its content. Furthermore, unlike the Hupp et al. $(2012,2013)$ studies, parents of children with ASD actually have to choose interventions for their children, rather than simply rate the interventions in the abstract.

On an Internet survey, parents of children with ASD reported the interventions they currently used, or had used in the past, for their children with ASD (Green et al., 2006). Green et al. compiled a list of 111 treatments used for autism. Of those interventions, 108 were endorsed by at least one parent, and parents reported using a few additional interventions that were not on the original list. Broad categories of interventions were medications, special diets, vitamin supplements, medical procedures, educational or therapy approaches, alternative therapies, and combined programs.

Among the 552 respondents, speech therapy was the most used intervention with $93 \%$ reporting that their children either were currently or had previously received speech therapy. Visual schedules (62\%), sensory integration (71\%), ABA (59\%), and social stories $(54 \%)$ rounded out the top five most utilized interventions. The mean number of interventions used at the time of the survey was seven. The authors noted that both the most and least commonly used interventions were a mix of empirically supported interventions and those without empirical support (Green et al., 2006). Interestingly, the severity of ASD symptoms was related to the number and type of interventions used. Children whose parents reported that they had more severe symptoms received more interventions. Additionally, parents whose children had autism were more likely than parents of children with Asperger's Syndrome to report that their child received skills 
training interventions based on the principles of applied behavior analysis. Regardless of symptom severity, the mean number of interventions used decreased as children aged (Green et al., 2006).

Green (2007) interviewed 19 parents of children with ASD regarding whether or not they used ABA, sensory integration, or Vitamin B6 with their children. All participants reported using at least one of the three types of therapy, and most used some combination of the three. Most parents found out about these interventions from other parents, the Internet, or books. The time required to implement the interventions ranged from 4-40 hours per week for ABA and 4-15 hours per week for sensory integration. Most parents also reported that sensory integration was fairly easy to implement. ABA, in contrast, was reported to be difficult to implement by most parents. Most parents reported positive gains from sensory integration and ABA, while slightly fewer than half reported positive outcomes from Vitamin B6. Green (2007) notes that it is it unclear from the interview data whether or not parents attempted to evaluate scientific information received from fellow parents or the Internet. She also mentions that there is no way of knowing if parents assumed interventions were valid when recommended by professionals rather than peers.

Hebert (2014) also studied the issue of how parents select interventions for their children with ASD or PDD-NOS qualitatively. Across two interviews per parent participant, Hebert found that factors influencing parent intervention choice could be combined into three general categories: parental attributes, child's attributes, and program/treatment attributes. Parental attributes included personal experiences, perceptions of autism, parenting style, perspectives on how children learn, and inner 
sense. For example, some parents whose parenting style was more authoritative did not like the structure of ABA, so they chose child-led approaches. Two parents cited a relationship between medical issues and autism. Those parents sought out biomedical interventions (Hebert, 2014).

Child attributes related to parental choice of interventions included age, developmental level, and child's needs. Some parents reported that they felt that the ABA approach was too strict and intense for their young children, so they chose child-directed interventions instead. Conversely, other parents said that they did not think their child had enough skills to derive benefit from child-directed therapy, and instead needed the structure of ABA. Some parents reported selecting therapies to address specific issues, such as sensory integration therapy (Hebert, 2014).

Program or treatment attributes related to parent choice included parent's perspective of therapeutic approaches, intensity, physical environment, social environment, teachers, and cost. Parents reported wanting their children's school or therapeutic environment to mirror that of typical children to the greatest extent possible. Parental acceptance of higher intensity and cost of interventions seemed to vary based on the severity of the child's symptoms, as well as their perceptions of the intervention's effectiveness (Hebert, 2014). Herbert also noted that parents of older children who had already tried traditional interventions were more likely to try alternative treatments. Although some parents who endorsed using alternative interventions were looking for a cure for autism, most just wanted to ensure their children reached their full potential.

McDonald, Pace, Blue, and Schwartz (2012) note that parents of children with ASD are often drawn to alternative therapies that offer "cures," regardless of the lack of 
scientific information supporting them. Information about alternative ASD interventions is easily accessible through the media, and the beliefs of celebrities are often given more credibility than they should. Additionally, professionals sometimes use interventions that are not empirically supported or tolerate their use by other professionals in their practice. McDonald et al. also noted that parents who believe that ASD has physiological causes are more likely to use biomedical interventions. Parents are attracted to this approach partially because of the success of dietary interventions in treating other concerns, such as diabetes and phenylketonuria (PKU) (McDonald et al., 2012).

McDonald et al. (2012) posit that the antidote to parents' use of non-empirically supported treatments is more information. They encourage the production of parentfriendly resources. Additionally, the authors support teaching parents to use scientific reasoning to select interventions for their children with autism. Although these recommendations may be helpful for some parents, they may not be enough to prevent parents from selecting interventions without empirical support, or interventions that have be shown to be ineffective or harmful (McDonald et al., 2012).

A study by Berquist and Charlop (2014) provides some support for the idea that parents can be taught to evaluate interventions using scientific principles. Parents in their study received several weeks of training via a step-by-step manual and direct instruction from a trainer. Parents' evaluation skills were measured both pre-and post-intervention by having them write out their process for evaluating their children's interventions. Researchers then assessed the extent to which parents' evaluation process aligned with the process they had been taught. After instruction, all parents who received the intervention demonstrated better use of scientific reasoning skills to determine the 
effectiveness of interventions. However, those gains did not maintain or generalize for two of the participants. Additionally, the researchers did not collect data on which interventions parents actually went on to use with their children.

Information about empirical support may contribute to parents' selection of interventions for their children with ASD. However, research has also linked beliefs about the causes of ASD to the types of interventions parents select. In a study by Al Anbar et al., (2010), parents who viewed ASD as more serious were more likely to use educational or behavioral interventions such as social skills training, Training and Education of Autistic and Related Communication Handicapped Children (TEAACH) approaches, or the Picture Exchange Communication System (PECS). Those who believed ASD followed a cyclical timeline were more likely to endorse medication use. Stronger beliefs in personal control over ASD predicted a decrease in use of treatments such as special diets and vitamins, as well as medication use. Parents who had more negative emotions related to ASD were less likely to use educational interventions. Parents who attributed their child's ASD to an external cause were more likely to use special diets and vitamins, as were those who believed ASD is hereditary. Al Anbar et al. also found that the older parents were, the less likely they were to solicit information from educators and other professionals.

\section{Therapeutic Approaches to ASD}

In the current study, parents were asked to rate the effectiveness of several ASD interventions. To contextualize parents' ratings of ASD interventions, in this section I outline the current evidence base for the $10 \mathrm{ASD}$ interventions parents were asked to rate. 
These therapies can be classified as (a) evidence-based interventions, (b) interventions with insufficient evidence, or (c) ineffective interventions.

\section{Evidence-Based Interventions}

Applied behavioral analysis (ABA). ABA encompasses many interventions, including antecedent modifications, task analyses, reinforcement procedures, and token economies. The National Standards Project, a subsidiary of the National Autism Center (NAC), lists all of these primary intervention strategies are evidence-based. However, some behaviorally based interventions, such as the Picture Exchange Communication System and social communication interventions, are listed as emerging treatments by the NAC.

Pivotal response training. Another evidence-based intervention is Pivotal Response Training (PRT). Pivotal Response Training targets crucial areas such as motivation for social communication, self-management, and self-initiation (NAC, 2009). Pivotal Response Training meets the NAC's standards for evidence-based interventions.

\section{Interventions With Insufficient Evidence}

Play therapy. According to a report by the Agency for Healthcare Research and Quality (AHRQ), play therapy is not currently empirically supported (Warren et al., 2011). Play-based therapies aim to improve children's joint attention and play skills during interactions with parents or other adults, usually in a play context. Although participants in studies reviewed in the report showed some improvement as compared to their peers who did not receive the therapy, no studies showed statistically significant differences. At this time, the AHRQ recommends that more research be done on playbased therapies. 


\section{Developmental/relationship therapies. The NAC listed}

developmental/relationship therapies as emerging interventions (NAC, 2009).

Developmental/relationship therapies generally involve child-directed activities and focus on building relationships with the child as the key therapeutic element. As an emerging intervention, the NAC recognizes that developmental/relationship therapies have some empirical support, but do not yet have enough to meet evidence-based standards.

Facilitated communication. Facilitated communication falls into the category of unestablished interventions (NAC, 2009). Unestablished interventions have no empirical support or have been shown to be ineffective. Facilitated communication involves a facilitator, generally a therapist who works with the child, guiding a child's hand or arm to type or press pictures with the idea that the child is communicating his thoughts. A review of studies examining the effectiveness of facilitated communication demonstrates that there is no support for this idea (Mostert, 2001).

Dolphin-assisted therapy. Dolphin-assisted therapy is not specifically mentioned by AHRQ report, but animal therapy is listed as an intervention with insufficient evidence. The reason given is that there is inadequate research available (Warren et al., 2011). Dolphin-assisted therapy involves children watching or interacting with dolphins. According to a review by Fiksdal, Houlihan, and Barnes (2012), effectiveness of dolphinassisted therapy cannot be evaluated at this time because no study to date has used adequate control groups.

Medication. Determining the evidence base for medication is difficult due to the variety of both symptoms of ASD and the medications used to treat them. According the AHRQ, some medications, such as aripiprazole and risperadone, have demonstrated 
effectiveness in managing symptoms of ASD. Others, including haloperidal and serotonin reuptake inhibiters, show some evidence of ameliorating ASD symptoms, but not enough to meet AHRQ's standards for evidence-based interventions (Warren et al., 2011).

Gluten-free casein-free diet. According to the NAC, a gluten-free casein-free diet is currently an unestablished treatment (NAC, 2009). Unestablished interventions have little or no empirical support, but they also have not been shown to be ineffective or harmful. Research on the effectiveness of dietary management is currently inconclusive. For example, an Internet survey of 387 parents of children with ASD asked parents about their child's adherence to a gluten-free casein-free (GFCF) diet, ASD symptoms, physiological symptoms, and social behaviors, as well as the length of time their children had been following a GFCF diet (Pennesi \& Klein, 2012). Overall, they found that parents who reported eliminating all foods containing gluten and casein also reported improvement in their child's ASD, physiological symptoms, and social behaviors. Additionally, parents who reported their child adhering to the diet for longer than six months reported a greater increase in improvement than did parents whose children had been following the diet for less than six months. However, the researchers mentioned that because of the self-report nature of the study it is impossible to verify adherence to the diet or reported behavioral and physiological changes. Additionally, changes could be due to the placebo effect.

Another study examining the effectiveness of a GFCF diet on symptoms of ADHD and ASD in children with ASD found that children who were between the ages of seven and nine were most likely to respond positively after 12 months of a GFCF diet, as compared to age groups younger and older. Additionally, higher baseline symptoms of 
ADHD corresponded to better response to the GFCF diet. The researchers noted more research is needed to differentiate between children who respond positively to a GFCF diet and those for whom it has no effect (Pedersen, Parlar, Kvist, Whitelely, \& Shattlock, 2014).

In a study using a double-blind design, Elder et al. (2006) assigned 13 children to six weeks of either a GFCF diet or a typical diet. Then, the children switched diets for the next six weeks. The data manager and the dietician in charge of preparing the children's food were the only people who knew when condition the children were in. Participants' ASD symptoms were measured both directly and indirectly before and during the trial. Researchers found no significant differences on child behaviors such as initiating, responding, or speaking intelligible words.

When parents were asked to identify which diet their child had been on during each time period, only five of the 13 were able to do so. Six incorrectly identified the time period during which their child had been on the GFCF diet, and two reported having no idea. Still, the researchers noted that nine of the families chose to keep their children on GFCF diet, even in the absence of empirical evidence (Elder et al., 2006). Although there were no significant differences in child behavior for the group as a whole, some behavior differences were noted in individual children. Additionally, some parents anecdotally reported improvements in their children's behavior. Elder et al. noted the need to examine individual differences, such as age, severity of ASD, and cognitive function, that might affect the effectiveness of a GFCF diet.

Vitamin B treatment. Vitamin B treatment involves giving children a Vitamin B-6 supplement, either in pill or shot form. According to the AHRQ, Vitamin B treatment 
has insufficient evidence. The report states that studies to date examining the effectiveness of Vitamin B treatment are of poor quality, and did not use comparison groups (Warren et al., 2011).

\section{Ineffective Interventions}

Secretin therapy. Secretin therapy involves providing children with intravenous doses of synthetic secretin, a gastrointestinal polypeptide used to treat ulcers. The AHRQ lists secretin therapy as an ineffective intervention (Warren et al., 2011). According the AHRQ, secretin therapy has been demonstrated to not lead to improvement in ASD symptoms.

\section{Cultural Cognition}

Parents' intervention choices for their children with ASD might be based on evaluation of the scientific evidence in addition to individual parent or child factors. However, as Fischhoff and Davis (2014) noted, values can also affect which interventions parents select. These values, conceptualized as cultural cognition, might help explain how parents choose interventions.

In several studies, Kahan and colleagues defined cultural cognition and examined its effects on people's decision-making regarding public policy issues (Kahan et al., 2012; Kahan et al., 2008). Cultural cognition refers to the way people's perception of facts and events are shaped by their values. The extent to which people's values are shaped by cultural cognition can be referred to as their cultural worldview. Underlying the cultural cognition thesis is the idea that people believe actions that fit with their values are beneficial, and those that do not are detrimental (Kahan et al., 2011).

Kahan et al. (2012) measure cultural cognition as two dimensions, hierarchy- 
egalitarianism and individualism-communitarianism, as seen in Figure 1. The hierarchyegalitarianism dimension measures the extent to which individuals endorse divisions in society. Generally, such divisions are based on fixed factors such as race, gender, and socioeconomic status. People who are more hierarchical are more likely to endorse such divisions, and people who are more egalitarian are less likely to do so. The individualismcommunitarianism dimension measures the extent to which people endorse autonomy and self-reliance, which in many studies is measured as how involved government is in people's lives. People who are more individualistic favor higher levels of autonomy and self-reliance and tend to believe that government involvement is unnecessary. People who are more communitarian generally believe that government involvement is beneficial to society. They also tend endorse the idea of collective responsibility.

\section{Individualism}

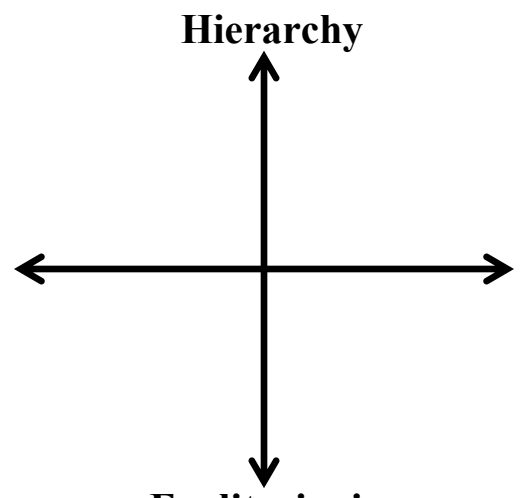

\section{Egalitarianism}

\section{Communitarianism}

Figure 1. The two dimensions of cultural cognition according to Kahan (2010). 
In one study, Kahan et al. (2012) examined the effect of cultural cognition on people's perception of what they described as the "speech-conduct distinction." According to Kahan et al., the First Amendment protects free speech, but not conduct. This means that it is necessary to distinguish between speech and conduct, a complicated endeavor. In this study, participants were shown a video of police ending a protest. In one condition, participants were told that the protesters were anti-abortion and were protesting in front of an abortion clinic. In the other condition, participants were told that protesters were against the military's ban on openly gay and lesbian soldiers and the demonstration took place on a college campus at a military recruitment center. The videos shown to both groups were identical, except for the text identifying the location as either the abortion clinic or the recruitment center. Participants in both conditions were told that the protesters were seeking an injunction against police for violating their right to free speech. They were also told that police ended the protest because they believed the protesters' actions crossed the line between speech and conduct. Additionally, participants were told that both the protesters and the police felt the video was an accurate representation of the events - but each side drew opposite conclusions about which party was in the right.

As the authors predicted, participants perceived the protest very differently based on where they fell on the dimensions of cultural cognition. Participants who were more hierarchical, who tend to support gender norms, more strongly supported the antiabortion demonstrators. Participants who were more communitarian also more strongly supported the anti-abortion demonstrators. According to Kahan et al. (2012), participants who were communitarian were more likely to support the anti-abortion demonstrators 
because they were more concerned about the effect of abortion on women's health. At the same time, participants who were more egalitarian and individualistic, who tend not to subscribe to social divisions, were less likely to support the anti-abortion demonstrators. The results were the opposite for those who viewed the demonstration in front of the recruitment center. Participants who were more egalitarian and individualistic were more likely to support protesters in the recruitment center videos. As participants endorsed more hierarchical and communitarian views, support for the recruitment center protesters lessened. The authors highlighted the point that although participants viewed the same videos, their cultural worldviews led them to draw completely different conclusions about whether or not the protesters had a case against the police for ending the demonstration. These findings shed some light on how the same information can be viewed by different people with vastly different results (Kahan et al., 2012). In the same way, parents' perceptions of interventions for their children with ASD could be influenced by their cultural worldviews. How parents view authority figures including doctors, teachers, and other professionals might affect their perceptions of the efficacy of certain interventions, regardless of the empirical support for those interventions.

In their study of public perception of the risks and benefits of nanotechnology, Kahan et al. (2008) found that simply exposing participants to information about either the risks and benefits of nanotechnology did not alter their perceptions of those risks and benefits as compared to participants who received no information beyond the definition of nanotechnology. This finding further supports the idea that providing people with more information on a topic does not necessarily change their beliefs about that topic. However, the researchers did find an interaction between cultural worldview and whether 
or not information was provided. When participants were given information about the risks and benefits of nanotechnology, hierarchical individualists perceived less risk and more benefits of nanotechnology, whereas egalitarian communitarians perceived the opposite. Similarly, the cultural worldviews of parents of children with ASD might interact with the information they receive about ASD interventions.

Dake (1992) also discusses perception of risk as being culturally constructed. Like Kahan et al. (2011), Dake posits that deciding in favor of or against a policy or technology goes beyond consideration of the facts. He argues that political and social factors are considered when people make decisions about the risks of issues such as climate change and technology. Dake believed that people's perceptions of environmental issues would align with their cultural worldview. For example, Dake hypothesized that people who were more hierarchical were more likely to view the environment as being more robust and resilient. From this perspective, only experts can determine the limits of the environment's resilience. Dake also hypothesized that people who were more egalitarian would be more likely to view nature as being fragile. As a result, they would support environmental policies that minimized risks for all.

Although cultural cognition is an important force that shapes people's attitudes toward various issues, a study by Kahan (2010) demonstrated that individual variables could have an affect on people's attitudes that cannot be explained by their cultural worldviews alone. Kahan asked participants if they endorsed involuntary outpatient commitment laws for people with serious mental illnesses. Participants were also asked to rate how much they knew about outpatient commitment laws before participating in the study, and whether they had any family members with serious mental illnesses. 
More knowledge about outpatient commitment laws was associated with lower concern about the effect of such laws on patients' liberty. Having a family member with a serious mental illness did not affect peoples' perceptions of the laws above and beyond the influence of their cultural worldviews. However, African American participants demonstrated support for outpatient commitment laws that could not be accounted for by cultural worldviews. African American participants, who tended to endorse more egalitarian worldviews, supported outpatient commitment laws despite their cultural worldviews. Kahan accounted for this finding by hypothesizing that African Americans, because of their disproportionate imprisonment rates, believe that outpatient commitment laws infringe less on their liberty than imprisonment.

Looking at the outpatient commitment law study, as well as others conducted by Kahan and colleagues, it is clear that knowledge of facts alone does not necessarily explain why people make the decisions they do. For parents of children with ASD, interpreting the evidence base for interventions could be influenced by their cultural worldviews. For example, their perception of whether an intervention is or is not evidence-based could be shaped by their perception of the credibility of the source of information. In turn, parents' perception of source credibility might be based on the extent to which the source's values are perceived to align with theirs.

\section{Research Questions and Hypotheses}

In the current study, I examined how parents' perceptions of interventions for ASD are related to their perceptions of ASD and their cultural worldview (i.e., hierarchyegalitarianism dimension and individualistic-communitarian dimension). Additionally, I 
compared the perceptions of parents whose children have ASD and those whose children do not have ASD.

I used three measures to investigate my research questions. Parents' perceptions of ASD were measured using an English translation of the Illness Perception Questionnaire, Revised for Autism (IPQ-RA) that Al Anabar et al. (2010) used in their study. The IPQ-RA is an adaptation of the IPQ-R, devised by Moss-Morris et al. (2002). It is based on Leventhal et al.'s (1997) Self-Regulatory Model of Illness Representations and it measures identity (associated symptoms), consequences, timeline (acute/chronic and cyclical), control/cure (personal and treatment control), cause, and emotional representations of the illness. I used two versions of the English translation of the IPQRA. The first version asked parents of children with ASD about their perceptions of their child's ASD specifically (hereafter referred to as IPQ-P). Only parents of children with ASD completed this version, and data obtained from it were used when analyzing hypotheses one and three. The second version asked all parents about their perceptions of ASD in general (hereafter referred to as IPQ). Both groups of parents completed this measure, and the data obtained from it were used when analyzing hypothesis four and my exploratory research questions.

Parents' cultural worldviews were measured using the Cultural Worldview Scales created by Kahan (2010). The 16-item Individualism-Communitarianism Scale measures the extent to which people endorse personal autonomy and independence. The 13 -item Hierarchy-Egalitarianism Scale measures the extent to which people endorse divisions in society and strict social roles. 
Finally, parents' perceptions of intervention efficacy were measured using modified versions of the STARS-CF created by Hupp et al. (2012). As noted above, the original measure included interventions for ODD, ADHD, and childhood depression as well as ASD. I used only the ASD interventions. Additionally, I asked parents if they had heard of each intervention as well as asking them if they perceived it to be effective. I used two versions of the modified STARS. The version given to parents of children with ASD (STARS-P) asked parents if they had heard of the intervention and how effective they perceived it to be for ASD generally. I also asked if they have used each intervention for their child. If they answered yes, they were asked how effective the intervention was for their child. If they answered no, they were asked how effective they thought it would be for their child. The data obtained from this measure were used to analyze hypotheses one, two, and three. The other version (STARS) was given to parents of children without ASD, and only asked parents if they had heard of the intervention and how effective they perceived it to be for ASD generally. It was used to analyze hypothesis four and my exploratory research questions.

Based on the current literature review of research on perceptions of ASD as a disorder, intervention selection, and cultural cognition, the following hypotheses were developed:

\section{Illness Perceptions}

I hypothesized that the results of the current study would replicate the findings of Al Anbar et al.'s (2010) research examining the relationship between illness perceptions of ASD and use of interventions. The specific predicted correlations appear in Table 1. Al Anbar et al. asked whether or not parents used certain interventions with children with 
ASD. In the proposed study, in contrast, participants were asked to rate the perceived effectiveness of these interventions on a 5-point scale.

\section{Illness perception (consequences) and perceptions of intervention efficacy.}

Al Anbar et al. found that parents who believed ASD was more serious were more likely to use educational or behavioral interventions such as ABA, social skills training, TEACCH, or PECS than those who believed ASD was less serious. I hypothesized that the consequences subscale of the IPQ-P would negatively correlate with perceptions of the efficacy of ABA and Pivotal Response Training on the STARS-P.

\section{Illness perception (cyclical timeline) and perceptions of intervention efficacy.}

Parents who believed ASD follows a cyclical timeline were more likely to endorse medication use (Al Anbar et al., 2010). My hypothesis was that participants who believe ASD follows a cyclical timeline would be more likely to perceive medication as an effective intervention; thus, these measures were predicted to be negatively correlated.

\section{Illness perception (personal control) and perceptions of intervention}

efficacy. Al Anbar et al. (2010) found that parents who endorsed high levels of personal control over ASD were less likely to use medications and metabolic treatments, including special diets. I hypothesized that those who endorsed higher levels of personal control over ASD would be less likely to perceive medication and GFCS diets as effective interventions. That is, I predict a negative correlation between a composite of parents' ratings of the efficacy of GFCF diet and medication and their scores on the IPQ-P personal control subscale. 


\section{Illness perception (emotional representations) and perceptions of}

intervention efficacy. Parents who had higher negative scores on the emotional representations subscale of the IPQ-RA were less likely to use educational or behavior interventions (Al Anbar et al., 2010). I hypothesized that people with a negative affect toward ASD would be less likely to perceive ABA and PRT as effective interventions. That is, parents' scores on the emotional representation subscale of the IPQ-P would be negatively correlated with perceived efficacy of ABA and PRT.

Perceived causation and perceptions of intervention efficacy. Regarding the relationship between causes of ASD and use of interventions, Al Anbar et al. (2010) found that external attributions of cause such as environmental pollution, viruses, and past poor medical care were associated with use of metabolic treatments such as special diets and vitamins. I hypothesized that participants who attribute ASD to external causes would be more likely to perceive dietary interventions (Vitamin B therapy and GFCF diets) as effective.

\section{Cultural Cognition}

I hypothesized that parents' perceptions of the efficacy of intervention effectiveness would be related to their cultural worldviews, as described by Kahan (2010) (see Table 2).

Cultural worldview and evidence-based interventions. ABA-based therapies and PRT both have strong empirical support and are likely to be endorsed by various types of ASD professionals. Because ABA-based therapies tend to be highly structured, it was hypothesized that individuals who endorse the effectiveness of ABA and PRT would be high on the hierarchical dimension of Kahan's (2010) measure of cultural worldview 
(and therefore low on egalitarianism; see Figure 2). Additionally, because ABA and PRT emphasize individualized interventions, people who endorse the effectiveness of ABA would be high on the individualistic dimension of Kahan's (2010) measure of cultural worldview (and therefore low on communitarianism; see Figure 3).

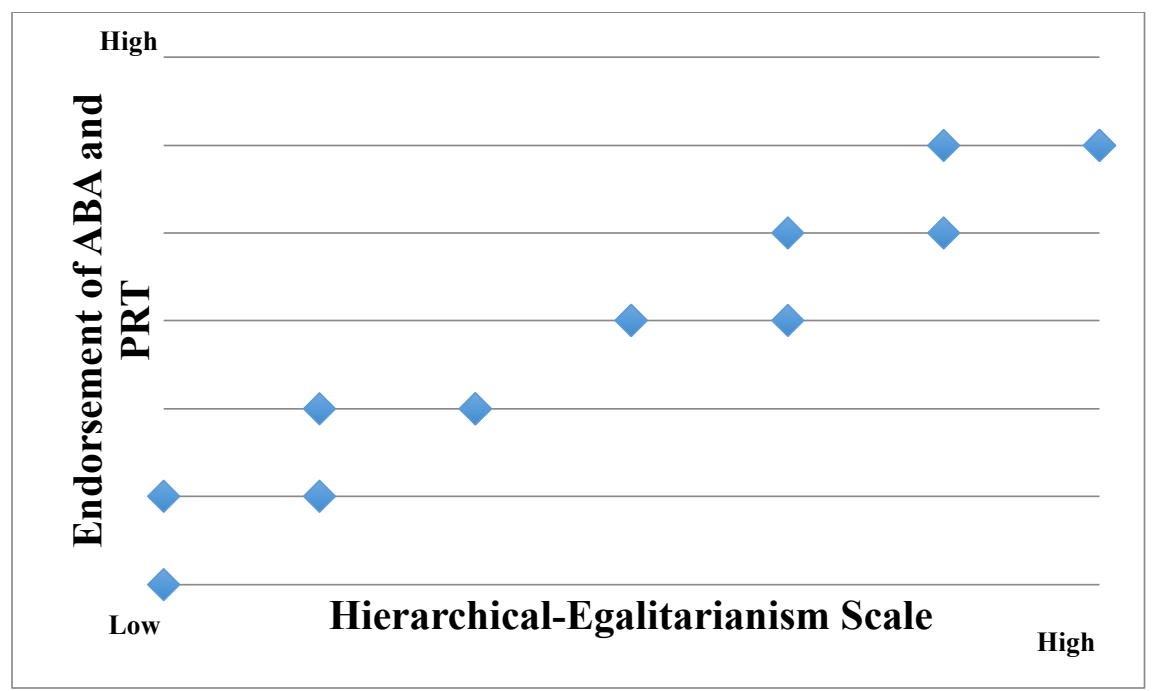

Figure 2. The predicted relationship between mean perceived efficacy of ABA and PRT and the H-E subscale of the Cultural Worldview Scales.

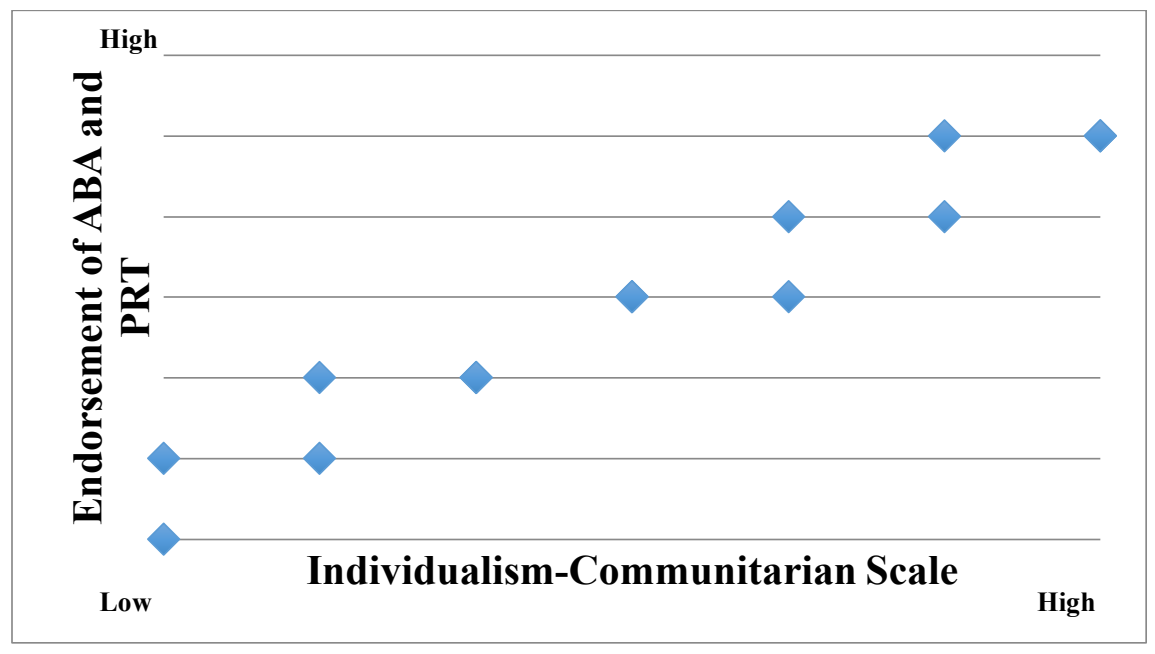

Figure 3. The predicted relationship between perceived efficacy of ABA and PRT and the I-C subscale of the Cultural Worldview Scales 


\section{Cultural worldview and non-evidence-based interventions. Because}

alternative therapies such as medication, diets (GFCF diets, Vitamin B therapy), and other therapies (Secretin Hormone Therapy, play therapy, developmental/relationship therapy, dolphin-assisted therapy, facilitated communication) currently have little to no empirical support, it was hypothesized that people who endorse these categories of treatment would be lower on the hierarchical dimension (and therefore high on egalitarianism; see Figure 4). People who are low on hierarchy might not believe that scientists' findings should be valued over their personal experiences. Additionally, since previous research has indicated that parents select interventions for their children using characteristics specific to their child and family (Hebert, 2014), it was hypothesized that people who endorsed alternative treatments would score higher on the individualistic dimension (and therefore low on communitarianism; see Figure 5). See Table 2 for predicted results.

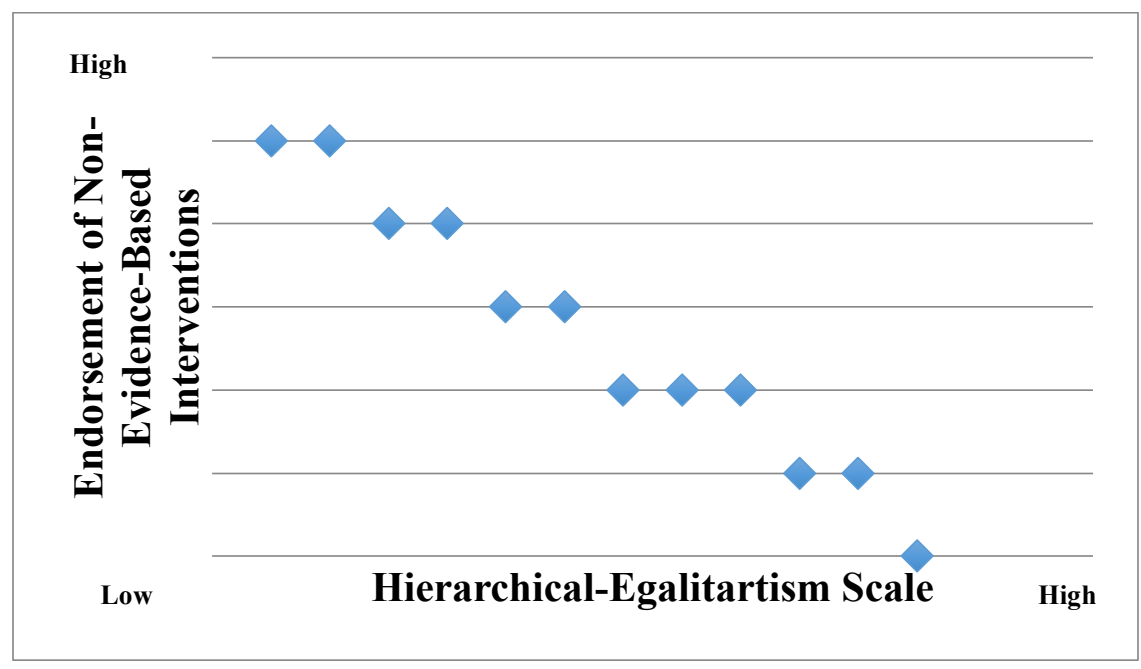

Figure 4. The predicted relationship between mean perceived efficacy of Non-EvidenceBased Interventions and the H-E subscale of the Cultural Worldview Scales. 


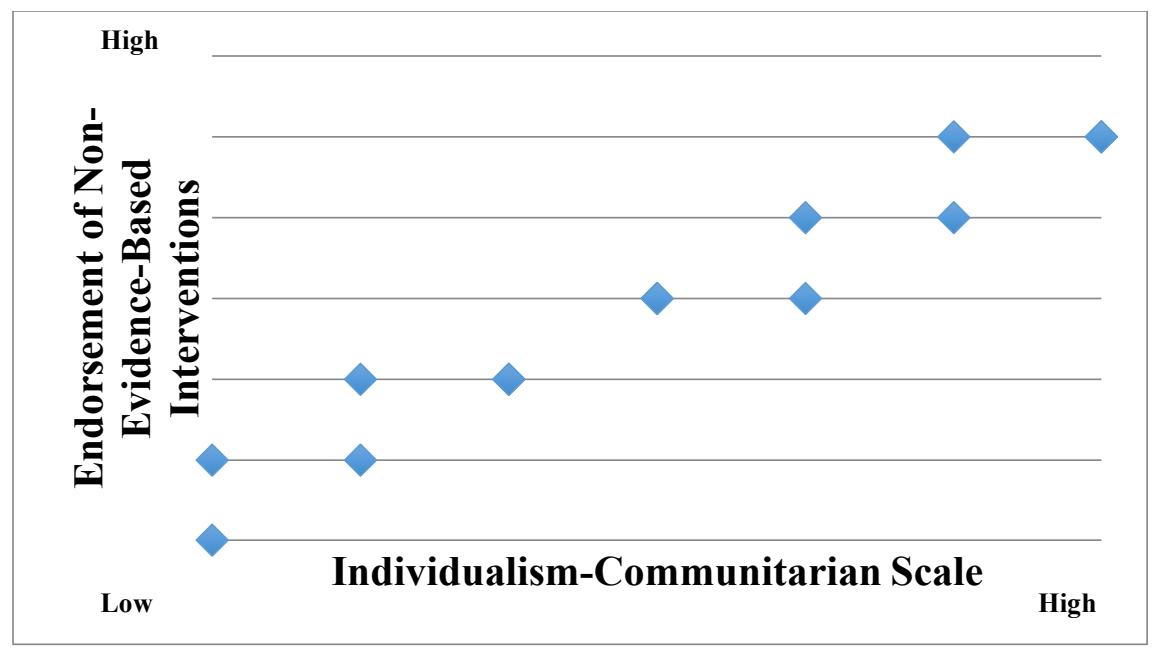

Figure 5. The predicted relationship between mean perceived efficacy of Non-EvidenceBased interventions and the I-C subscale of the Cultural Worldview Scales.

\section{Predictors of Intervention Efficacy by Parents of Children With ASD}

I hypothesized that parents' emotional representations (i.e., negative affect), perceptions of consequences, and cultural worldview would make independent contributions to the variance in parents' perceptions of intervention efficacy. I also hypothesized that cultural worldview would predict perceived efficacy of evidence-based interventions even after controlling for parents' emotional representations and perceptions of consequences.

\section{Differences Between Parent Groups}

I also hypothesized that there would be differences between parent groups (representing first-hand experience with ASD or not) with regards to the predictive relationships between cultural cognition, illness perceptions, and perceptions of the efficacy of interventions. 


\section{Cultural worldview, experience with ASD, and perceived intervention}

efficacy. Because parents of children without ASD are likely to have less knowledge about treatments, I hypothesized that the correlations between cultural cognition and ratings of intervention efficacy would be weaker or non-significant compared to the same relationship for parents of children with ASD. For example, parents of children without ASD may not know that ABA involves hierarchical and individualistic characteristics.

\section{Illness perception (emotional representations), experience with ASD, and} perceived intervention efficacy. I also hypothesized that the emotional representations of ASD of parents of children without ASD would predict less of the variance in perceptions of the efficacy of ABA and PRT than it would for parents of children with ASD. Parents of children without ASD would likely have weaker affective responses to ASD than parents of children with ASD.

\section{Exploratory Research Questions}

In addition to the specific predictions above, I explored two research questions for which I did not have specific predictions. First, do people perceive the nonempirically supported treatments as a single category, or do they treat them as different types of interventions (i.e., diet, medicine, therapy)? For hypotheses 1 and 2, I made $a$ priori assumptions that medication may be rated differently from diet and supplements, and that these two categories may be treated differently than the other therapies because the causal agent underlying each is different. However, it remains to be seen how these categories of intervention are perceived by parents (with or without children with ASD). For example, parents whose children do not have ASD may believe that medications may be effective. Likewise, a lack of experience with some of the non-empirically supported 
therapies that "sound good" or have plausible sounding names (e.g., facilitated communication) may result in higher ratings by parents without firsthand experience with ASD. In order to address this question, an exploratory factor analysis was conducted on the STARS measure to examine the factor structure of these items. Second, I wanted to explore which factors (e.g., experience with ASD, cultural worldview, illness perceptions) are related to ratings of the effectiveness of non-empirically supported treatments. To address this question, I conducted two multiple regressions using the same predictor variables (i.e., emotional representations, consequences, and cultural worldview scores and parent group) to predict ratings of perceived effectiveness of non-empirically supported interventions on the STARS and STARS-P. 


\section{CHAPTER III}

\section{METHOD}

\section{Participants}

In the current study, 74 parents of children with ASD and 126 parents of children without ASD participated. Most participants were female $(N=65,87.25 \%$ for parents of children with ASD and $N=111,88.09 \%$ for parents of children without ASD). The average age of participants was $45.00(S D=9.27)$ for parents of children with ASD and $39.00(S D=9.25)$ for parents of children without ASD. Most participants were married (74.75 percent for parents of children with ASD and 86 percent for parents of children without ASD). Approximately $69 \%$ of parents of children with ASD and $39 \%$ of parents of children without ASD reported having a family member or close friend with other serious physical, intellectual, or developmental disabilities or mental illnesses.

Because I recognized that both parents of children with and without ASD might have other experiences with ASD outside of raising a child with the disorder that might affect their perceptions of intervention, participants were also asked about their paid and unpaid experiences with ASD. Experience included babysitting, teaching or working as a therapist, volunteering at day camps, or having a friend who had a child with ASD. Approximately $11 \%$ of parents of children with ASD reported having unpaid experience with ASD, with an average of approximately six years of experience. Thirty-five percent 
of parents of children with ASD reported having paid experience with ASD, with an average of 3.5 years of experience. Thirty-eight percent of parents of children without ASD reported having unpaid experience with ASD, with an average of six years of experience. Fifty-four percent of parents of children without ASD reported having paid experience with ASD, with an average of four years of experience.

On average, parents of children with ASD had two children and one child with ASD. Parents of children without ASD had approximately two children on average. The children with ASD were approximately nine-years-old on average $(S D=4.35)$ and the children without ASD were approximately seven-years-old $(S D=1.59)$. Sixty-three percent of children with ASD were male as were $48 \%$ of children without ASD. Parents of children with ASD reported an average of eight years since their children's diagnosis and rated their children's severity of ASD as a 2.51 out of five (with one being not severe and five being very severe) on average $(S D=1.22)$.

\section{Measures}

\section{Illness Perception Questionnaire-Revised for Autism, English Version (IPQ-RAE)}

This assessment is an English translation of the French IPQ-RA created by Al Anbar, Dardennes, Prado-Netto, Kaye, and Contejean (2010). The IPQ-RA is an adaptation of the IPQ-R, devised by Moss-Morris et al. (2002). The IPQ-R assesses the six components of Leventhal et al.'s (1997) Self-Regulatory Model of illness representation. The components are: identity, consequences, timeline (acute/chronic and cyclical), control/cure (personal and treatment control), and cause. It also measures emotional representations of illnesses. In the current study, the all components except identity were examined. The IPQ-R and its adaptations have been used to measure 
people's perceptions of their own illness and those of their spouses (e.g., Hagger \& Orbell, 2005; Sterba \& Devllis, 2009). The IPQ-R also has been used to assess the illness perceptions of people with rheumatoid arthritis, type II diabetes, asthma, chronic and acute pain, multiple sclerosis, and myocardial infarctions, among others (Moss-Morris et al., 2002). The IPQ-R measures whether or not people experience certain symptoms, how they perceive their illness, and to what causes they attribute their illness. The subscales have been found to be reliable (consequences, $\alpha=.84$; timeline acute/chronic, $\alpha=.89$; timeline cyclical, $\alpha=.79$; personal control, $\alpha=.81$; treatment control, $\alpha=.80$; and emotional representations, $\alpha=.88$ ). The original identity subscale composed on nondisorder-specific health issues was also found to be reliable $(\alpha=.75)$ (Moss-Morris et al., 2002). Moss-Morris et al. found that four factors composed the causes subscale: psychological attributions, $\alpha=.86$; risk factors, $\alpha=.77$; immunity, $\alpha=.67$; and accident or chance, $\alpha=.23$. However, the Al Anbar et al. (2010) study reporting finding only three factors that composed the causes subscale: personal attributions, $\alpha=.89$; external attributions, $\alpha=.82$; and hereditary attributions, $\alpha=.70$. The external attributions factor, which will be used as a predictor variable in the current study, is comprised of the items from the Immunity factor along with the "past poor medical care" item that loaded on to the Risk-Factor factor in the Moss-Morris et al. (2002) study.

Al Anbar et al. (2010) modified the symptom list to reflect symptoms commonly experiences by children who have ASD. They also altered the phrase "my illness" to "my child's disorder." The word disorder was chosen instead of illness because ASD is considered to be a disorder, and labeling it as an illness may be offensive to parents. For 
the purposes of this study, the English version of the French IPQ-RA that was given to parents of children with ASD will be referred to as the IPQ-P.

\section{Illness Perception Questionnaire for Healthy People-Revised for Autism, English Version (IPQ-RAEH)}

Another version of the IPQ-R has been used to assess healthy people's perceptions of illnesses. Figueiras and Alves (2007) created the Revised Illness Perception Questionnaire for healthy people (IPQ-RH). They assessed healthy adults' perceptions of one of three illnesses: AIDS, tuberculosis, or skin cancer. Participants were asked to what extent symptoms were associated with a given illness, their perceptions of the illness, and the causes of the illness. An adapted version of this measure, the Illness Perception Questionnaire for Healthy People-Revised for Autism, was be used to measure all participants' illness perceptions related to ASD. For the purposes of this study, it will be simply referred to as the IPQ. As in the IPQ-RA (Al Anbar et al. 2010), the symptom list was replaced with symptoms commonly experienced by people with ASD. Participants were asked to what extent they perceive people with ASD to experience those symptoms. Perceptions of ASD and its causes were also measured. Participants who are parents of children with ASD completed the IPQ-P and IPQ; Parents of children without ASD only completed the IPQ.

Specific Therapeutic Approaches Rating System-Child Form-ASD Subscale-Revised (STARS-CFA-R)

To measure parents' perception of ASD interventions, a measure adapted from the Specific Therapeutic Approaches Rating Scale-Child Form (STARS-CF) was used (Hupp, Stary, Bradshaw, \& Owens, 2012). The STARS-CF includes interventions for 
Oppositional Defiant Disorder, Attention Deficit/Hyperactivity Disorder, and Depression as well as ASD; only the interventions for ASD were used. The 10 listed interventions are a mix of evidence-based and non-evidenced based interventions for ASD. Participants were asked if they had heard of each intervention. Then, they were asked to rate each intervention's effectiveness on a five-point Likert scale from zero (not effective), to four (effective). Because parents of children without ASD in particular were likely to be unfamiliar with most of the treatments listed, each treatment was accompanied by a brief (one or two sentence) description. For the purposes of this study, this measure will be referred to as the STARS. Additionally, previous research has found that individual and contextual differences affect the behavior of children with ASD (Kanne, Abbacchi, \& Constantino, 2009). This means not all children with ASD will react to interventions the same way. To account for this, parents of children with ASD were also asked if each intervention was effective for their child. For the purposes of this study, the version of this measure for parents of children with ASD will be referred to as the STARS-P.

Two of the treatments listed in the STARS and STARS-P are empirically supported, but the rest are either emerging or non-supported interventions. Empirically supported interventions are ABA and PRT (NAC, 2009). Developmental/relationship and play therapies both need more evidence to support their effectiveness, as do GFCF diets and Vitamin B6 therapy (NAC, 2009; Warren et al., 2011). Although dolphin-assisted therapy is not specifically mentioned in their review, Warren et al. (2011) list animal therapy as an intervention with insufficient evidence. Secretin treatment has been found to be ineffective (Warren et al., 2011). The evidence base for medications is more 
complex. Some medications, such as risperidone, are listed as effective interventions, whereas others, like fluoxetine, currently have insufficient evidence (Warran et al., 2011).

\section{Cultural Cognition}

To measure participants' worldviews, I used the Cultural Worldview Scales designed by Kahan (2010). The 16-item Individualism-Communitarianism Scale measures the extent to which people endorse personal autonomy and responsibility. People who score higher on individualism endorse more personal autonomy and responsibility than those who are higher on communitarianism. The 13-item HierarchyEgalitarianism Scale measures the extent to which people endorse divisions in society. People who score higher on hierarchy endorse more divisions in society, and those who score higher on egalitarianism endorse fewer. All items on both scales use a six-point scale ranging from Strongly Agree to Strongly Disagree. These scales have been previously used to measure the relationship of people's cultural worldviews with their attitudes toward outpatient commitment laws, nanotechnology, gun control, climate change, mandatory HPV vaccinations, and protesters (Kahan, 2010; Kahan, et al., 2011; Kahan, Braman et al., 2008; Kahan et al., 2012). The scales have been found to be highly reliable measures of participants' worldviews (Individualism, $\alpha=.88$; Hierarchy, $\alpha=.89$ ) (Kahan et al, 2010). For the current study, the Hierarchy-Egalitarianism scale was found to reliable $(\alpha=.77)$, but the Individualism-Communitarianism scale was not $(\alpha=.58)$. The implications of this finding will be addressed in the Discussion chapter.

\section{Procedure}

Parents of children with ASD were recruited through organizations such as The Autism Program of Illinois (TAP) and the Autism Society of McLean County. After 
obtaining permission from email list administrators, e-mails were sent to people on the organizations' e-mail lists. Parents of children with and without ASD were recruited though Illinois State University's Computer Infrastructure and Support Services (CISS). E-mails inviting participants were sent to faculty and staff members who have not opted out of research participation invitations. Additionally, parents of children with and without ASD were recruited by posting on social media.

All questionnaires were administered via online surveys. Participants were asked to choose a link based on whether they have a child with any ASD Spectrum Disorder (autism, Asperger's Syndrome, pervasive developmental disorder-not otherwise specified, Rhett's or childhood disintegrative disorder). A second link was chosen if their child had no specific diagnosis, or a different diagnosis (e.g., ADHD, intellectual disability, depression, etc.). After selecting the appropriate link, participants were initially directed to a page providing informed consent. They were told that they would be asked questions about ASD, ASD treatments, and their worldviews. Participants were also informed that they could leave the study at any time with no risk of repercussions. They were asked to verify that they were at least 18 years old.

After verifying their age and consenting to participate, participants were asked demographic questions including parent age, child age, race/ethnicity, and whether or not any of their family members have a serious mental or physical illness or developmental disorder other than ASD. All parents were given the IPQ. Parents of children with ASD were also given the IPQ-P, which asked about their child specifically. The order in which the IPQ and the IPQ-P were presented to parents of children with ASD was counterbalanced to prevent order effects. Once they completed the IPQ and/or IPQ-P, 
participants were asked to complete either the STARS if they did not have a child with ASD or STARS-P scale if they did. They were then given the Cultural Worldview Scales. Upon completion of that measure, they were thanked for their time and provided with more information about the rationale of the study. 


\section{CHAPTER IV}

\section{RESULTS}

The results will be presented in four sections. First, I will provide descriptive statistics on the various measures for parents with and without children with ASD. In the second section, I address the first exploratory research question by presenting the results of an exploratory factor analysis on the STARS and STARS-P. Hypothesis 2 and the second exploratory research question rely upon knowing whether or not participants perceived particular treatments in a similar way (e.g., are treatments that involve ingesting a substance treated similarly?). In the third section, I present results related to hypotheses 1 through 4, as outlined in Chapter 2. Finally, I present results related to the second exploratory research question.

\section{Descriptive Statistics}

Table 3 lists the means and standard deviations of participants' scores on the IPQ and IPQ-P consequences, cyclical timeline, personal control, emotional representations, and external attributions subscales. As can be seen, there are not many differences between parents of children with and without ASD. However, parents of children with ASD did have significantly more negative emotional representations of ASD than do parents of children without ASD, $t(195)=7.94, p<.001$. Additionally, parents of children with ASD viewed ASD as having a significantly more cyclical timeline than did parents of children without ASD, $t(195)=2.47, p=.015$. Parents of children with ASD 
had views that were quite similar when they considered their own child's ASD and ASD in general, with the exceptions of their perceptions of the consequences of ASD and the extent to which they perceive ASD as being externally caused. Interestingly, parents of children with ASD perceived the consequences of ASD as significantly more severe for ASD in general than for their own child, $t(71)=-2.38, p=.020$. They also perceived ASD in general as significantly more likely to have been externally caused than their child's ASD, $t(64)=-2.63, p=.011$.

Table 4 lists the percentage of participants who reported having heard of each STARS intervention, as well as their average ratings of the interventions' efficacy. The same information is reported for participants who completed the STARS-P, along with the percentage of parents who reported their child having received each intervention and their average perceived efficacy of those interventions for their children. For most of the interventions, the percentage of parents of children without ASD who had heard of the intervention was similar to the percentage of parents of children with ASD. However, in the case of PRT and Vitamin B Therapy, more parents of children without ASD had heard of the interventions than had parents of children with ASD. The unexpected knowledge of ASD interventions might be due to the finding that over half of participants who did not have a child with ASD had some sort of paid experience with ASD, and approximately 40 percent had unpaid experience with ASD.

Table 5 lists the means and standard deviations of participants' scores on the Hierarchy-Egalitarianism and Individualism-Communitarianism subscales. Parents of children without ASD were, on average, significantly more hierarchical than parents of children with ASD, $t(184)=-12.03 p<.001$. This unexpected finding and its possible 
implications for hypotheses two, three, and four will be discussed more fully in Chapter 5. There was no significant difference between parents of children with and without ASD on the Individualism-Communitarianism scale.

\section{Exploratory Factor Analysis}

I first conducted an exploratory factor analysis using principle axis factor analysis with varimax rotation with Kaiser normalization for the STARS and STARS-P questionnaires. The exploratory factor analysis produced two factors. The first was comprised of play therapy, developmental/relationship therapy, facilitated communication, pivotal response training, and applied behavior analysis. The second was comprised of GFCF diet, dolphin-assisted therapy, medication, Secretin Hormone Therapy, and Vitamin B Therapy. Thus, the first factor comprised all evidence-based interventions or emerging interventions, with the exception of facilitated communication. As will be discussed further in Chapter 5, people might have perceived facilitated communication as evidence-based because it sounds similar to other interventions that do have empirical support (e.g., functional communication training). The second factor was used when analyzing Hypothesis $2 \mathrm{~b}$ and the exploratory research questions.

\section{Tests of Hypotheses}

1. My first hypothesis was that my findings would replicate those of previous research on illness perceptions and ASD by Al Anbar et al. (2010). The following hypotheses only concern parents of children with ASD, so the STARS-P and IPQ-P were used as outcome measures. See Table 6 for the relevant correlations for Hypotheses 1a through 1e. 
a. I hypothesized that participants who perceived ASD as having more serious consequences would be more likely to endorse the use of ABA and PRT. I correlated participants' scores on the consequence subscale of the IPQ-P with a composite score representing their perceptions of the efficacy ABA and PRT on the STARS-P. Although a positive correlation was predicted, the resulting correlation was not statistically significant, $r=.166, p=.399$. This hypothesis was not supported.

b. I hypothesized that participants who perceived ASD as following a more cyclical timeline would be more likely to perceive medication as an effective intervention. I correlated participants' scores on the cyclical timeline subscale of the IPQ-P with their responses on the medication item on the STARS-P. The correlation was predicted to be positive, but a non-significant negative correlation was found $(r=$ $-.085, p=.602)$. This hypothesis was not supported.

c. I hypothesized that participants who endorsed higher levels of personal control over ASD would be less likely to endorse the use of medication and GFCS diets. I correlated participants' scores on the personal control subscale of the IPQ-P with a composite score representing participants' perceptions of the efficacy of GFCF diet and medication on the STARS-P. Although the correlation was predicted to be negative, a significant correlation was not found $(r=-.158, p=.404)$. This hypothesis was not supported.

d. I hypothesized that participants with a more negative affect toward ASD would be less likely to endorse the uses of ABA and PRT. I correlated participants' scores on the emotional representations subscale of the IPQ-P with a composite score 
representing their perceptions of the efficacy of ABA and PRT on the STARS-P. The correlation was predicted to be negative, but a non-significant negative correlation was found $(r=-.205, p=.296)$. This hypothesis was not supported. As an exploratory analysis, the emotional representations subscale scores and perceptions of ABA and PRT of parents of children without ASD were correlated. There was a significant negative correlation between participants' scores on the emotional representations subscale and their perceptions of ABA and PRT for parents of children without ASD $(r=-.240, p=.012)$.

e. I hypothesized that participants who attribute ASD to external causes would be more likely to endorse the use of Vitamin B therapy and GFCF diets. I correlated participants' perceptions of the efficacy of external factors as causing ASD with a composite score representing participants' perceptions of the efficacy of GFCF diet and Vitamin B Therapy on the STARS-P. The correlation was predicted to be positive, and a significant correlation was found $(r=.334, p=.007)$. This hypothesis was supported. Additionally, as an exploratory analysis, I correlated parents of children without ASD's perceptions of the efficacy of external factors as causing ASD with a composite score representing participants' perceptions of the efficacy of GFCF diet and Vitamin B Therapy on the STARS. A significant positive correlation was found for parents of children without ASD $(r=.252, p=$ $.006)$.

2. My second hypothesis was that participants' perceptions of the efficacy of interventions would be related to their cultural worldviews (see Table 7). 
a. I hypothesized that the evidence-based treatments, ABA and PRT, were more likely to be perceived as effective by those who endorse more hierarchical and individualistic worldviews (for predicted pattern, see Figures 2 and 3). I correlated participants' score on Kahan's (2010) Hierarchy-Egalitarianism scale with a composite score representing their mean perceptions of the efficacy of ABA and PRT on the STARS-P. I then correlated the composite score with their score on Kahan's (2010) Individualism-Communitarianism scale. Although both correlations were predicted to be positive, a non-significant negative correlation was found for Hierarchy-Egalitarianism, $r=-.239, \mathrm{p}=.229$, and a non-significant positive correlation for Individualism-Communitarianism, $r=.093, p=.650$. This hypothesis was not supported.

b. I also hypothesized that therapies that are not evidence-based were more likely to be perceived as effective by those who endorse more egalitarian and individualistic worldviews. I correlated participants' score on Kahan’s (2010) Hierarchy-Egalitarianism scale with a composite score representing their mean perceptions of the efficacy of unestablished interventions (either emerging or ineffective interventions) as defined by the Phase II of the NAC's National Standards Project (2015). These interventions were facilitated communication, dolphin-assisted therapy, and GFCF diet on the STARS-P. There was no relationship between parents' endorsement of NAC unestablished interventions and their scores on the Hierarchy-Egalitarianism scale $(r=.217, p=.085)$. Additionally, I correlated the same scores with participants' scores on Kahan's (2010) Individualism-Communitarianism scale. There was a significant 
relationship between parents' endorsement of the efficacy of NAC unestablished interventions and their Individualism-Communitarianism scores such that parents who scored higher on Individualism were more likely to endorse unestablished interventions $(r=.320, p=.010)$. Participants' scores on a composite of nonevidence-based interventions derived from a factor analysis were also correlated with their Hierarchy-Egalitarianism scores and Individualism-Communitarianism scores. This composite included GFCF diet, dolphin-assisted therapy, medication, Vitamin B therapy, and Secretin Hormone Therapy. For parents of children with ASD, the relationship was positive and non-significant, $r=.235 p=.061$. For parents of children without ASD, there was a positive relationship between egalitarianism and endorsement of the efficacy of alternative interventions, $r=$ $.233, p=.014$. There was no significant relationship between endorsement of efficacy of alternative interventions by parents of children with or without ASD and their scores on the Individualism-Communitarianism scale.

3. My third hypothesis was that cultural cognition would be a predictor of perceptions of evidence-based intervention effectiveness even after controlling for parents' emotional representations and perceptions of consequences. I conducted a two-step hierarchical regression using participants' scores on the emotional representations subscale of the IPQ-P, and their scores on the consequence subscale of the IPQ-P to predict perceptions of the efficacy of ABA and PRT on the STARS-P in the first step. Emotional representations and perceptions of the consequences of ASD did not significantly contribute to the regression model at step one. Next, scores on Kahan's (2010) Hierarchy-Egalitarianism and Individualism-Communitarianism scales were 
entered as predictors of participants' perceptions of the efficacy of ABA and PRT. At this step, emotional representations and both cultural worldview subscales contributed significantly to the regression model. Table 8 shows the regression statistics for hypothesis three. This hypothesis was not supported.

Recall that a significant difference was found between parents of children with autism and parents of children without autism on the Hierarchy-Egalitarianism subscale, such that parents of children with autism had significantly lower scores on the Hierarchy-Egalitarianism subscale. The implications of this finding will be discussed in Chapter 5.

4. My fourth hypothesis was that there would be differences between parent groups with regard to the predictive relationships between cultural worldview, illness perceptions, and perceived effectiveness of evidence-based interventions. For these analyses, the IPQ and STARS measures completed by both parent groups were used.

a. I hypothesized that cultural worldview would account for less of the variance in perceived intervention effectiveness for parents of children without ASD than it would for parents of children with ASD. There was no significant relationship between cultural worldview and perceived intervention effectiveness for parents of children with ASD (Hierarchy-Egalitarianism: $r=-.175, p=.190$; Individualism-Communitarianism: $r=.119, p=.376$ ). Additionally, there was no significant relationship between cultural worldview and perceived intervention effectiveness for parents of children without ASD (Hierarchy-Egalitarianism: $r=-$ $.011, p=.912$; Individualism-Communitarianism: $r=-.043, p=.658$ ). This hypothesis was not supported. 
b. I also hypothesized that emotional representations of ASD by parents of children without ASD would predict less of the variance in perceptions of the efficacy of ABA and PRT than it would for parents of children with ASD. I addressed this prediction by conducting a three-step hierarchical regression using participant's scores on the emotional representations subscale of the IPQ in the first step. Emotional representations did not significantly contribute to the model at step one. Participants' scores on Kahan's (2010) Hierarchy-Egalitarianism and Individualism-Communitarianism subscales were then entered as predictors of participants' perceptions of the efficacy of ABA and PRT. At this step, there was a significant predictor for the Hierarchy-Egalitarianism subscale, but the overall model was not significant. Finally, participants' experience with ASD (i.e., parent group) was added as a predictor variable. At this step, the regression model has no significant predictors. Table 9 shows regression statistics for hypothesis four. This hypothesis was not supported.

\section{Exploratory Research Questions}

My first exploratory research question, whether or not parents perceived non-

evidence-based interventions differently, was addressed by the exploratory factor analysis discussed above. To answer the question about the factors that predict ratings of perceived effectiveness of non-empirically supported interventions, I conducted two multiple regressions using the same predictor variables (i.e., emotional representations, cultural worldview scores and parent group). The first three-step hierarchical regression used a composite variable created using the results of the factor analysis discussed earlier as the dependent variable. The interventions that comprised this composite variable 
included GFCF diet, dolphin-assisted therapy, medication, Secretin Hormone Therapy, and Vitamin B Therapy. Emotional representations were added at the first step, and were a significant predictor (see Table 10). At the second step, the Hierarchy-Egalitarianism and Individualism-Communitarianism subscale scores were entered and the emotional representations and Individualism-Communitarianism variables were significant predictors. At the third step, parents' status as having a child with or without ASD was added, but only emotional representations and Individualism-Communitarianism significantly contributed to the model.

The second three-step hierarchical regression used a composite of interventions based on the NAC's (2015) list of unestablished interventions as the dependent variable. These included facilitated communication, dolphin-assisted therapy, and GFCF diet. Emotional representations were entered at step 1 and were a significant predictor (see Table 11). At the second step, the Hierarchy-Egalitarianism and IndividualismCommunitarianism subscale scores were entered and all three variables were significant predictors. At the third step, parents' status as having a child with or without ASD was added, but only emotional representations and Individualism-Communitarianism significantly contributed to the model. Thus, the results were the same regardless of the method used to group non-evidence-based interventions. 


\section{CHAPTER V \\ DISCUSSION \\ General Discussion}

The reported incidence rate of ASD has increased over the past 15 years (CDC, 2014). This increase has been accompanied by the emergence of many interventions designed to address ASD, either by reducing associated symptoms or attempting to "cure" the disorder (Green et al., 2006). Previous researchers have examined factors that influence how parents make intervention decisions for their children with ASD (e.g., A1 Anbar et al., 2010; Green, 2007; Hebert, 2014). Previously identified predictors of intervention selection include parents' perceptions of ASD as a disorder. Although the idea of cultural cognition has not been examined in relation to ASD, it has been used as predictors of people's views on a variety of scientific and political issues (e.g. Kahan 2010, Kahan et al., 2008, Kahan et al., 2011, Kahan et al., 2012).

In the current study, I examined the relationship between perceptions of ASD as a disorder and parents' perceptions of the efficacy of certain ASD interventions. I also examined the relationship between parents' cultural worldview and their perceptions of the efficacy of interventions. Although parents of children with ASD are the primary focus of this study, I also examined the relationship between a parents' experience with ASD (measured by whether or not they have a child with ASD) and their perceptions of the efficacy of interventions to explore possible differences between the two parent groups. 
I hypothesized that my findings regarding the relationship between parents' perceptions of intervention efficacy (as measured by the STARS) and their perceptions of ASD as a disorder (as measured by the IPQ) would replicate those of Al Anbar et al. (2010). This hypothesis was only partially supported. Unlike Al Anbar et al., I did not find a relationship between parents' perceptions of the consequences of ASD and their perceived efficacy of evidence-based interventions. I also did not find a relationship between parents' scores on the cyclical timeline subscale of the IPQ and their perceived efficacy of medication. There was no relationship between parents' levels of personal control over ASD and their perceived efficacy of GFCF diet and medication. I did not find that parents of children with ASD who had more negative emotions toward ASD were less likely to perceived evidence-based interventions as effective. However, parents of children without ASD who had more negative feelings about ASD did perceive evidence-based interventions as less effective. Additionally, parents of children with and without ASD who attributed ASD to external causes were more likely to perceived GFCF diet and Vitamin B Therapy as effective.

One reason that my findings might not have replicated those of Al Anbar et al. (2010) is that that they had parents rate their use of various interventions, whereas my study focused on parents' perceived efficacy of interventions (regardless of use). Parents might use interventions they do not perceive as effective because they are recommended by experts or peers, or they might not use interventions they perceive to be effective because of time or financial constraints. Additionally, Al Anbar et al.'s study was conducted in French with participants from France. My study was conducted in English in a primarily United States-based sample, although some participants indicated they 
were from other countries. It is possible that there are cultural differences in the way ASD and ASD interventions are perceived that accounted for the lack of replication. For example, the researcher who published the since-debunked study linking ASD to vaccines, Andrew Wakefield, relocated to and has been working in the United States after having his medical credentials removed in the United Kingdom. It could be that his influence, along with that of other outspoken celebrities who reject vaccinations and support non-evidence-based interventions, is more strongly felt in the United States than in France. It is also possible that in the time between when Al Anbar et al. collected their data and I collected mine, attitudes toward ASD and ASD interventions shifted.

I also hypothesized that parents' perceptions of the efficacy of interventions would be related to their cultural worldviews. This hypothesis was only partially supported. Specifically, I hypothesized that parents' who endorsed hierarchical and individualistic worldviews would be more likely to perceive evidence-based interventions as effective. I did not find any relationship between parents' cultural worldviews and their perceived efficacy of evidence-based interventions.

Additionally, I hypothesized that parents who endorsed egalitarian and individualistic worldviews would be more likely to perceive non-evidence-based interventions as effective. There was no relationship between parents' endorsement of NAC unestablished interventions (i.e., facilitated communication, dolphin-assisted therapy, and GFCF diet) and their scores on the Hierarchy-Egalitarianism scale. However, parents who endorsed more individualistic cultural worldviews were more likely to perceived NAC unestablished interventions as effective. Participants' scores on a composite of non-evidence-based interventions derived from a factor analysis (GFCF 
diet, dolphin-assisted therapy, medication, Vitamin B Therapy, and Secretin Hormone Therapy) were also correlated with their Hierarchy-Egalitarianism scores and Individualism-Communitarianism scores. There was no relationship between either of the cultural worldview scores and parents' perceptions of the efficacy of the factor analysisderived composite for parents of children with ASD. However, parents of children without ASD who endorsed more egalitarian worldviews were more likely to perceive non-evidence-based interventions as effective.

The lack of relationship between cultural worldview and parents' perceptions of the efficacy of evidence-based interventions could have been due to the unexpected relationship between parents' status of having children with or without ASD and their cultural worldviews. Although there was no reason to expect that parents of children with ASD would significantly differ from parents of children without ASD on cultural worldviews, previous studies have indicated that participant characteristics can affect how participants' cultural worldviews influence their perceptions of issues (e.g., AfricanAmericans and outpatient commitment laws; Kahan, 2010). Additionally, I found unexpectedly low reliability for the Individualism-Communitarianism subscale score of the Cultural Worldview Scales. This measure has been used in many published studies, with good reliability for the two studies for which it was reported (Kahan, 2010; Kahan et al., 2012).

My third hypothesis was that cultural worldview would predict parents' perceptions of evidence-based intervention efficacy even after controlling for their emotional representations and perceived consequences of ASD. Although parents' emotional representations were a significant predictor of their perceived efficacy of 
evidence-based interventions at step two of the regression analysis, they were not significant at step one. None of the other predictors were significant at either step, so the hypothesis was not supported. The finding that emotional representations were a significant predictor at step two when they were not at step one could have occurred because emotional representations were weakly correlated with parents' perceptions of ABA and PRT and strongly correlated with parents' scores on the HierarchyEgalitarianism scale or the Individualism-Communitarianism scale.

Finally, I hypothesized that there would be differences between parent groups with regard to the predictive relationships between cultural worldview, illness perceptions, and perceived effectiveness of evidence-based interventions. I did not find a relationship between parents' perceived efficacy of evidence-based interventions and their cultural worldview for parents of children with or without ASD. I also hypothesized that emotional representations of ASD by parents of children without ASD would predict less of the variance in perceptions of the efficacy of ABA and PRT than it would for parents of children with ASD. I did not find support for this prediction.

The results of the exploratory factor analysis demonstrated that participants' perceived interventions as falling into two categories. The first category was comprised of evidence-based or emerging interventions, with the exception of facilitated communication. However, facilitated communication sounds similar to functional communication training, which is a behavioral intervention described by the NAC as having emerging empirical support. Additionally, given that communication is one of the core deficits seen in ASD, people unfamiliar with facilitated communication might conclude that it is an evidence-based intervention. Hupp et al. (2012) found that after a 
group of college students took a child psychology course that covered ASD and ASD interventions, they actually endorsed facilitated communication more strongly than they had before taking the class. It was not until researchers conducted a similar study in which students learned about the lack of empirical support for certain ASD interventions that participants rated facilitated communication as less effective (Hupp et al., 2013).

I used the second factor found in the exploratory factor analysis to conduct a hierarchical regression with emotional representations, cultural worldview scores, and parent group as the predictor variables. The second factor was comprised of GFCF diet, dolphin-assisted therapy, medication, Secretin Hormone Therapy, and Vitamin B Therapy. Participants' emotional representations of ASD and their cultural worldviews all contributed significantly, but their status as parents of children with or without ASD did not.

Although the factor analysis answered the question regarding how parents perceive interventions as being categorized, I also wanted to know how emotional representations, cultural worldviews, and parent status affected parents' perceptions of interventions listed by the NAC as non-evidence-based. These included facilitated communication, dolphin-assisted therapy, and GFCF diet. Once again, parents' emotional representations and Individualism-Communitarianism subscale scores contributed significantly, and their parent status did not. In this analysis, participants' HierarchyEgalitarianism subscale score did not significantly contribute. The lack of significance of parent status in both analyses could be due to the fact that 38 percent of parents of children without ASD had unpaid experience with ASD and 54 percent had paid experience with ASD. Parents of children without ASD who had extensive experience 
with ASD might have views more similar to those held by parents of children with ASD than parents of children without ASD who did not have experience with ASD.

\section{Strengths and Limitations of the Current Study}

One of the strengths of the current study is its relatively large sample of parents of children with ASD. Additionally, the online survey design allowed for participants to be recruited outside of the usual pool of university students. Although I did not ask where participants were from, some participants wrote in the comments section of their surveys that they were from other countries.

Another strength of the current study is that it included parents of children without ASD. Generally, studies on perceptions of interventions focus on parents of children with ASD or teachers. Focusing on parents of children without ASD as well made it possible to compare the attitudes and perceptions of parents of children with ASD to those of parents of children without ASD. It is important to do so because even if parents do not have a child with ASD, they might influence intervention decisions for children with ASD through their roles as teachers, therapists, family members, or friends of parents of children with ASD. Given that over half of the participants in my study who did not have children with ASD had some experience with children with ASD, this is especially true.

Finally, the current study was also unique because I examined how cultural worldview influences parents' perceptions of interventions. Cultural worldview has previously been found to affect how people perceive other medical, social, and scientific issues. 
One major limitation of the current study is the length of the survey. Several participants commented that it was too long, especially participants of children with ASD who had to complete the IPQ-P and an extended version of the STARS in addition to the measures all participants took.

Additionally, several participates commented that they felt the cultural worldview questions were irrelevant, intrusive, or offensive. Participants who described themselves as living outside the United States particularly said that the questions were not relevant to them. Many participants who completed the rest of the survey did not complete the cultural worldview questions. However, because the Cultural Worldview Scales were the last measures in the survey, it is unknown whether participants stopped taking the survey due to their negative perceptions of the questions or because of the length of the survey.

Another limitation of the current study is the unexpected relationship between parents' Hierarchy-Egalitarianism scores and their status as having a child with or without ASD. This finding possibly accounts for the lack of significant results for some hypotheses and certainly makes it more difficult to interpret the results. Additionally, the inadequate reliability of the Individualism-Communitarianism scale means that the analyses that included the measure need to be interpreted cautiously.

Participants' knowledge of certain ASD interventions was also a limitation of the current study. Although the majority of participants had heard of ABA, only 41 percent of parents of children without ASD and 27 percent of parents of children with ASD had heard of PRT, the other evidence-based intervention. Participants' lack of knowledge about interventions might have affected their perceptions of efficacy. 


\section{Directions for Future Research}

Because the survey length made it more difficult to retain participants, future research should either shorten the measures used or focus on fewer measures in each study. For example, although the current study allowed me to look at the relationships between more variables, future research focusing on the relationships between just cultural worldviews and intervention efficacy or perceptions of ASD as a disorder and cultural worldview might allow for better participant retention.

To determine if participants did not complete the Cultural Worldview Scales because they did not like the questions or if it was due to survey length, future studies should vary the order in which the scales are presented. Additionally, it might be helpful to limit use of the Cultural Worldview Scales to participants in the United States.

Future researchers should also conduct studies to attempt to replicate the relationship between having a child with ASD and egalitarian worldviews. If this finding replicates, it might have implications for the way parents perceive ASD interventions. For example, parents might have more negative views of interventions that appear to have strict rules about who runs the intervention or whose views of interventions are important.

Another possible avenue for future research is examining the differences in people's perceptions of interventions they have heard of and/or used as compared to those they have not. For example, parents of children with ASD perceived the efficacy of Secretin Hormone Therapy as between "probably not effective" and "don't know." However, only two parents actually reported having used Secretin Hormone Therapy with their children, and both reported that it was not effective for their children. 
Future research could also focus on separating parent groups further by parents of children with and without ASD who have different types and amount of experience with ASD. As previously noted, it is possible that parents of children without ASD who have worked with children with ASD have perceptions of ASD and ASD interventions more like those of parents of children with ASD than those without. It would also be interesting to how professionals who work with children with ASD, such as teachers and therapists, perceive ASD and ASD interventions.

\section{Conclusions}

The prevalence of ASD has increased over the past several years. At the same time, parents of children with and without ASD are exposed to information about many evidence-based and non-evidence-based interventions. Knowing how parents perceive the efficacy could help educators and therapists who work with children with ASD help parents make decisions about interventions for their children. The results of the current study did support Al Anbar et al.'s (2010) finding that parents of children with ASD who have more negative emotional representations of ASD are less likely to support evidencebased interventions. Additionally, parents who held more individualistic worldviews were more likely to perceive NAC unestablished interventions as being ineffective. These findings, along with the finding that parents of children with ASD were held more egalitarian worldviews than those of parents of children without ASD, demonstrate the need for future research on parents' perceptions of the efficacy of ASD interventions. 


\section{REFERENCES}

Al Anbar, N. N., Dardennes, R. M., Prado-Netto, A., Kaye, K., \& Contejean, Y. (2010). Treatment choices in Autism Spectrum Disorder: The role of parental illness perceptions. Research in Developmental Disabilities, 31, 817-828. DOI:10.1016/j.ridd.2010.02.007.

American Psychiatric Association. (2013). Diagnostic and statistical manual of mental disorders (5th ed.). Arlington, VA: American Psychiatric Association.

Berquist, K. L, \& Charlop, M. H. (2014). Teaching parents of children with autism to evaluate interventions. Journal of Developmental and Physical Disabilities, 26, 451472. DOI: $10.1007 / \mathrm{s} 10882-014-9374-4$.

Bruine de Bruin, W. \& Bostrom, A. (2013). Assessing what to address in science communication. PNAS, 110,14062-14068. www.pnas.org/cgi/doi/10.1073/pnas.1212729110.

Centers for Disease Control and Prevention (2014). Autism spectrum disorder: Data \& statistics. http://www.cdc.gov/ncbddd/autism/data.htm.

Dake, K. (1992). Myths of nature: Culture and the social construction of risk. Journal of Social Issues, 48, 21-37.

Elder, J., H., Shankar, M., Shuster, J., Theriaque, D., Burns, S., \& Sherrill, L. (2006). The Gluten-free, casein-free diet in autism: Results of a preliminary double blind clinical trial. Journal of Autism and Developmental Disorders, 36, 413-420. DOI: 10.1007/s10803-006-0079-0.

Figueiras, M. J. (2007). Lay perceptions of serious illness: An adapted version of the Revised Illness Perception Questionnaire (IPQ-R) for healthy people. Psychology \& Health, 22, 143-158. DOI:10.1080/14768320600774462.

Fiksdal, B. L., Houlihan, D., \& Barnes, A. C. (2012). Dolphin-assisted therapy: Claims versus evidence. Autism Research and Treatment, 2012, 1-7.

DOI:10.1155/2012/839792.

Fischhoff, B. \& Davis, A. L. (2014). Communicating scientific uncertainty. PNAS, 11, 13664-13671. www.pnas.org/cgi/doi/10.1073/pnas.1317504111.

Green, V. A., Pituch, K. A., Itchon, J., Choi, A., O’Reilly, M., \& Sigafoos, J. (2006). Internet survey of treatments used by parents of children with autism. Research in Developmental Disabilities, 27, 71-84. DOI:10.1016/j.ridd.2004.12.002. 
Green, V. A., (2007). Parental experience with treatments for autism. Journal of Developmental \& Physical Disabilities, 19, 70-84. DOI 10.1007/s10882-007-9035-y.

Hagger, M. S. \& Orbell, S. (2005). A confirmatory factor analysis of the revised illness perception questionnaire (IPQ-R) in a cervical screening context. Psychology and Health, 20, 161-173. DOI: 10.1080/0887044042000334724.

Hebert, E. B. (2014). Factors affecting parental-decision making regarding interventions for their child with autism. Focus on Autism and Other Developmental Disabilities, 29, 451-472. DOI: 10.1177/1088357614522291.

Hupp, S. D., Stary, A. K., Bradshaw, K. N., \& Owens, S. A. (2012). Debunk, debunk, debunk: Some evidence for why dissemination is only half the battle. The Behavior Therapist, 35, 76-78. ISSN 0278-8403.

Hupp, S. D. A., McKenney, E., Schmittel, M., McCobin, A., \& Owens, S. A. (2013). Disseminate, debunk, differentiate: Teaching about evidence-based treatments in a child psychology course. The Behavior Therapist, 36, 14-16. ISSN 0278-8403.

Kahan, D. M. (2010). Cultural cognition and public policy: The case of outpatient commitment laws. Faculty Scholarship Series. Paper 96. http://digitalcommons.law.yale.edu/fss_papers/96

Kahan, D. M., Braman, D., \& Jenkins-Smith, H. (2011). Cultural cognition of scientific consensus. Journal of Risk Research, 14, 147-174. DOI: 10.1080/13669877.2010.511246.

Kahan, D. M., Braman, D., Slovic, P., Gastil, J., \& Cohen, G. (2008). Cultural cognition of the risks and benefits of nanotechnology. Nature Nanotechnology, 4, 87-90. DOI: 10.1038/NNANO.2008.341.

Kahan, D. M., Hoffman, D. A., Braman, D., Evans, D., \& Rachlinksi, J. J. (2012). “They saw a protest": Cognitive illiberalism and the speech-conduct distinction. Stanford Law Review, 64, 851-906.

Kanne, S. M., Abbachi, A. M., \& Constantino, J. N. (2009). Multi-informant ratings of psychiatric symptom severity in children with autism spectrum disorders: The importance of environmental context. Journal of Autism and Developmental Disorders, 39, 856-864. DOI 10.1007/s10803-009-0694-7.

Leventhal, H., Benyamini, Y., Brownlee, S., Diefenbach, M., Leventhal, E. A., PatrickMiller, L., \& Robitaille, C. (1997). Illness representations: theoretical foundations. Perceptions of health and illness, 2, 19-46.

McDonald, M. E., Pace, D., Blue, E. \& Schwartz, D. (2012). Critical issues in causation and treatment of autism: Why fads continue to flourish. Child \& Family Behavior Therapy, 34, 290-304. DOI: 10.1080/07317107.2012.732849. 
Moss-Morris, R., Weinman, J., Petrie, K.J., Horne, R., Cameron, L.D., \& Buick, D. (2002). The revised illness perception questionnaire (IPQ-P-R). Psychology and Health, 17, 1-16. DOI: 10.1080/08870440290001494.

Mostert, M. P. (2001). Facilitated communication since 1995: A review of published studies. Journal of Autism and Developmental Disorders, 31, 287-313. DOI: 01623257/01/0600-0287\$19.50/0.

National Autism Center. (2009). National standards report: The national standards project-Addressing the need for evidence-based practice guidelines for autism spectrum disorders. Retrieved from http://www.nationalautismcenter.org/pdf/NAC\%20Standards\%20Report.pdf

National Autism Center. (2015). Findings and conclusions: National standards project, phase 2. Randolph, MA: Author

Pedersen, L., Parlar, S., Kvist, K., Whiteley, P., \& Shattlock, P. (2014). Data mining the ScanBrit study of gluten-free and casein-free dietary intervention for children with autism spectrum disorders: Behavioural and psychometric measures of dietary response. Nutritional Neuroscience, 17. 207-213.

DOI:10.1179/1476830513Y.0000000082.

Pennesi, C. M. \& Klein, L. C. (2012). Effectiveness of the gluten-free, casein-free diet for children with autism spectrum disorder: Based on parental report. Nutritional Neuroscience, 15, 85-91. DOI 10.1179/1476830512Y.0000000003

Sterba, K. R. \& DeVellis, R. F. (2009). Developing a spouse version of the Illness Perception Questionnaire-Revised (IPQ-R) for husbands of women with rheumatoid arthritis. Psychology \& Health, 24, 473-487. DOI: 10.1080/0887044070186778

Taylor, B. (2006). Vaccines and the changing epidemiology of autism. Child: Care, Health \& Development, 32, 511-519. DOI: 10.1111/j.1365-2214.2006.00655.x von Winterfeldt, D. (2013). Bridging the gap between science and decision making. PNAS, 110,14055-14061. www.pnas.org/cgi/doi/10.1073/pnas.1213532110

Warren, Z., Veenstra-VanderWeele, J., Stone, W., Bruzek, J. L., Nahmias, A. S., FossFeig, J. H.,... McPheeters, M. (2011). Therapies for children with autism spectrum disorders. Comparative Effectiveness Review Number 26. AHRQ Publication No. 11-EHC029-EF. Rockville, MD: Agency for Healthcare Research and Quality. Retrieved from http://www.effectivehealthcare.ahrq.gov/ehc/products/106/656/CER26_ Autism_Report_04-14-2011.p 
Table 1

Predicted Results for Hypothesis 1

\begin{tabular}{|c|c|c|c|c|c|c|c|c|c|c|}
\hline & 1 & 2 & 3 & 4 & 5 & 6 & 7 & 8 & 9 & 10 \\
\hline 1 Identity (IPQ-P) & -- & & & & & & & & & \\
\hline 2 Consequences (IPQ-P) & & -- & & & & & & & & \\
\hline 3 Personal Control (IPQ-P) & & & -- & & & & & & & \\
\hline 4 Timeline cyclical (IPQ-P) & & & & -- & & & & & & \\
\hline $\begin{array}{l}5 \text { Emotional representations } \\
\text { (IPQ-P) }\end{array}$ & & & & & -- & & & & & \\
\hline 6 External cause (IPQ-P) & & & & & & -- & & & & \\
\hline 7 Evidence-based (STARS-P) & & *+ & & & $*_{-}$ & & -- & & & \\
\hline 8 Dietary (STARS-P) & & & & & & $*+$ & & -- & & \\
\hline 9 Therapies (STARS-P) & & & $*_{-}$ & & & & & & -- & \\
\hline 10 Medication (STARS-P) & & & & & $*_{+}$ & & & & & -- \\
\hline
\end{tabular}


Table 2

Predicted Results for Hypothesis 2

\begin{tabular}{lcccc}
\hline & 1 & 2 & 3 & 4 \\
\hline 1 H-E & -- & & & \\
2 I-C & & -- & & \\
3 Evidence-based (STARS-P) & $*+$ & $*+$ & -- & -- \\
4 Non-Evidence-Based (STARS-P) & $*_{-}$ & $*+$ & & -
\end{tabular}

Note. $\mathrm{H}-\mathrm{E}=$ Hierarchy-Egalitarianism; $\mathrm{I}-\mathrm{C}=$ Individualism-Communitarianism 
Table 3

IPQ and IPQ-P Subscale Means and Standard Deviations

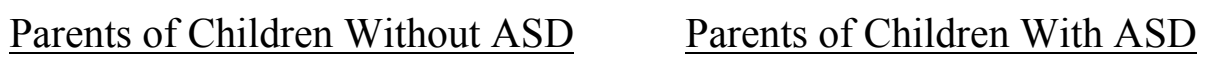

\begin{tabular}{|c|c|c|c|c|}
\hline $\begin{array}{l}\text { IPQ and IPQ-P } \\
\text { Subscale Scores }\end{array}$ & Mean & $\mathrm{SD}$ & Mean & $\mathrm{SD}$ \\
\hline $\begin{array}{l}\text { Consequences } \\
\text { (IPQ) }\end{array}$ & 4.07 & .57 & 4.20 & .67 \\
\hline $\begin{array}{l}\text { Consequences } \\
\text { (IPQ-P) }\end{array}$ & - & - & 4.02 & .76 \\
\hline $\begin{array}{l}\text { Timeline-Cyclical } \\
\text { (IPQ) }\end{array}$ & 2.94 & .70 & 3.22 & .89 \\
\hline $\begin{array}{l}\text { Timeline-Cyclical } \\
\text { (IPQ-P) }\end{array}$ & - & & 3.19 & .84 \\
\hline $\begin{array}{l}\text { Personal Control } \\
\text { (IPQ) }\end{array}$ & 3.76 & .62 & 3.83 & .74 \\
\hline $\begin{array}{l}\text { Personal Control } \\
\text { (IPQ-P) }\end{array}$ & - & - & 3.78 & .69 \\
\hline \multicolumn{5}{|l|}{ Emotional } \\
\hline $\begin{array}{l}\text { Representations } \\
\text { (IPQ) }\end{array}$ & 2.24 & .67 & 3.09 & .67 \\
\hline \multicolumn{5}{|l|}{ Emotional } \\
\hline $\begin{array}{l}\text { Representations } \\
\text { (IPQ-P) }\end{array}$ & - & - & 3.12 & .80 \\
\hline \multicolumn{5}{|l|}{ External } \\
\hline $\begin{array}{l}\text { Attributions } \\
\text { (IPQ) }\end{array}$ & 2.36 & .78 & 2.41 & .85 \\
\hline \multicolumn{5}{|l|}{ External } \\
\hline $\begin{array}{l}\text { Attributions* } \\
\text { (IPQ-P) }\end{array}$ & - & - & 2.30 & .90 \\
\hline
\end{tabular}

Note. The Illness Perception Questionnaire (IPQ) was administered to all parents. The IPQ-P was the version given only to parents of children with ASD. *A composite score of four items on the causes subscale of the IPQ-P external attribution. 


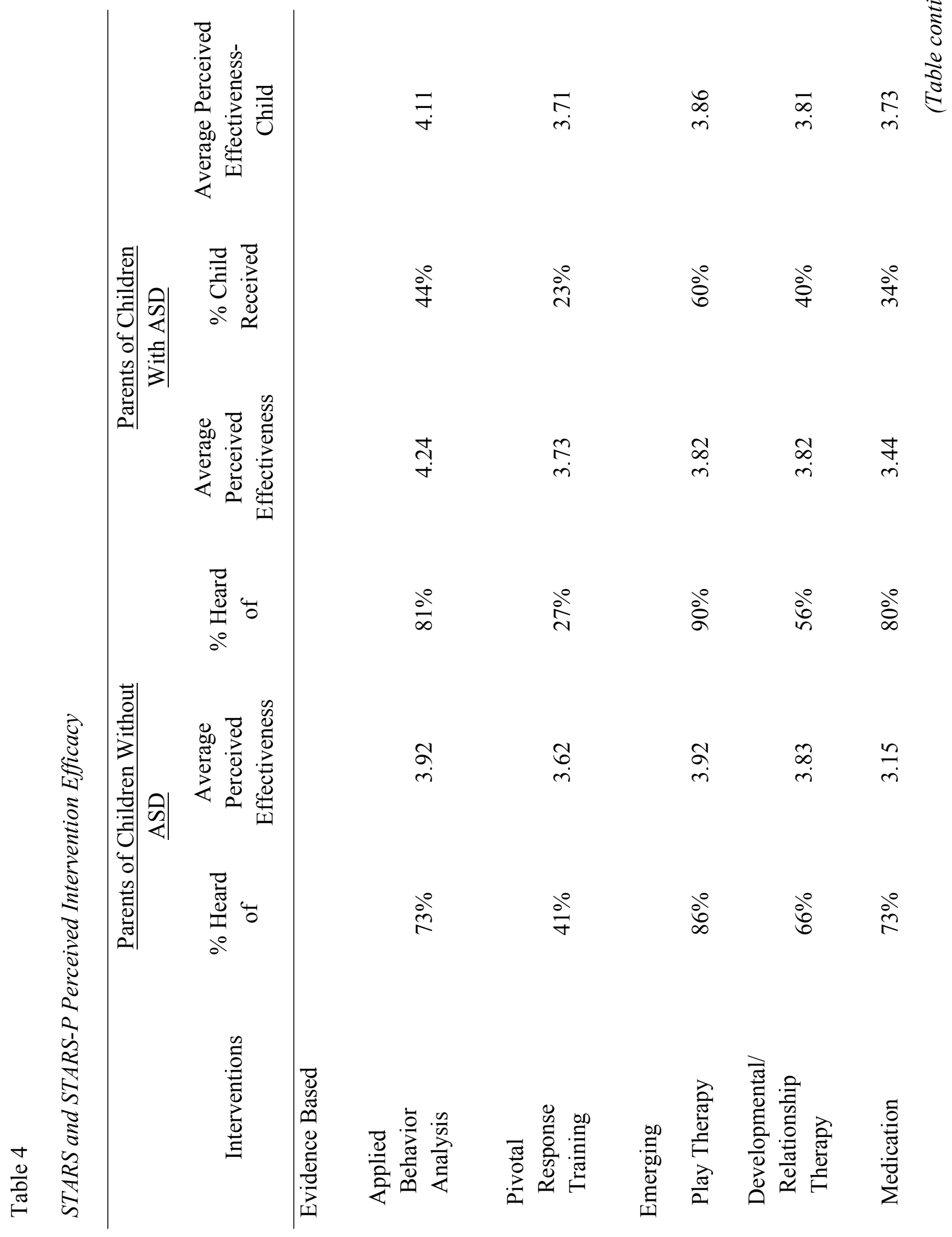




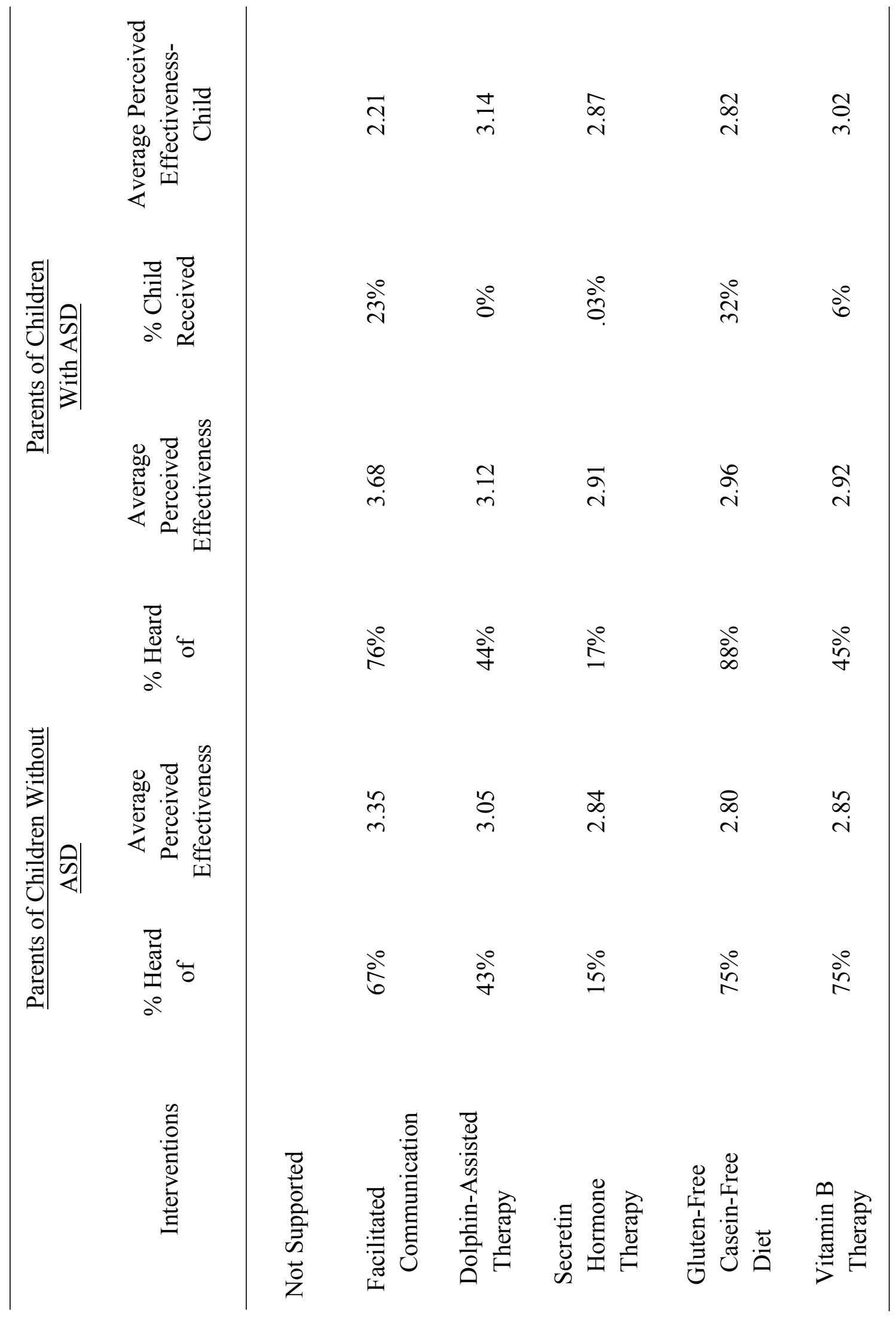


Table 5

Cultural Worldview Subscale Means and Standard Deviations

\begin{tabular}{|c|c|c|c|c|}
\hline \multirow[b]{2}{*}{$\begin{array}{l}\text { Cultural Worldview } \\
\text { Subscale Scores }\end{array}$} & \multicolumn{2}{|c|}{ Parents of Children Without ASD } & \multicolumn{2}{|c|}{$\underline{\text { Parents of Children With ASD }}$} \\
\hline & Mean & SD & Mean & SD \\
\hline $\begin{array}{l}\text { Hierarchy- } \\
\text { Egalitarianism }\end{array}$ & 3.72 & .46 & 2.51 & .90 \\
\hline $\begin{array}{l}\text { Individualism- } \\
\text { Communitarianism }\end{array}$ & 3.42 & .50 & 3.35 & .68 \\
\hline
\end{tabular}

Note. Hierarchy-Egalitarianism: $\alpha=.77 ;$ Individualism-Communitarianism: $\alpha=.58$ 
Table 6

Actual Results for Hypothesis 1

\begin{tabular}{|c|c|c|c|c|c|c|c|c|c|c|}
\hline & 1 & 2 & 3 & 4 & 5 & 6 & 7 & 8 & 9 & 10 \\
\hline 1 Identity (IPQ-P) & -- & & & & & & & & & \\
\hline 2 Consequences (IPQ-P) & & -- & & & & & & & & \\
\hline 3 Personal Control (IPQ-P) & & & -- & & & & & & & \\
\hline 4 Timeline Cyclical (IPQ-P) & & & & -- & & & & & & \\
\hline $\begin{array}{l}5 \text { Emotional Representations } \\
\text { (IPQ-P) }\end{array}$ & & & & & -- & & & & & \\
\hline 6 External Cause (IPQ-P) & & & & & & -- & & & & \\
\hline $\begin{array}{l}7 \text { Evidence-Based } \\
\text { (STARS-P) }\end{array}$ & & .17 & & & -.21 & & -- & & & \\
\hline 8 Dietary (STARS-P) & & & & & & $* .33$ & & -- & & \\
\hline 9 Therapies (STARS-P) & & & & -.16 & & & & & -- & \\
\hline 10 Medication (STARS-P) & & & & & -.09 & & & & & -- \\
\hline
\end{tabular}


Table 7

Actual Results for Hypothesis 2

\begin{tabular}{llllll}
\hline & 1 & 2 & 3 & 4 & 5 \\
\hline $1 \mathrm{H}-\mathrm{E}$ & -- & & & \\
$2 \mathrm{I}-\mathrm{C}$ & & -- & & \\
3 Evidence-Based (STARS-P) & -.24 & .09 & -- & \\
4 NAC Unestablished (STARS-P) & .22 & $* .32$ & & -- & \\
$\begin{array}{l}\text { Non-Evidence-Based (Factor } \\
\text { Analysis) (STARS-P) }\end{array}$ & .24 & .22 & & & - \\
\hline
\end{tabular}




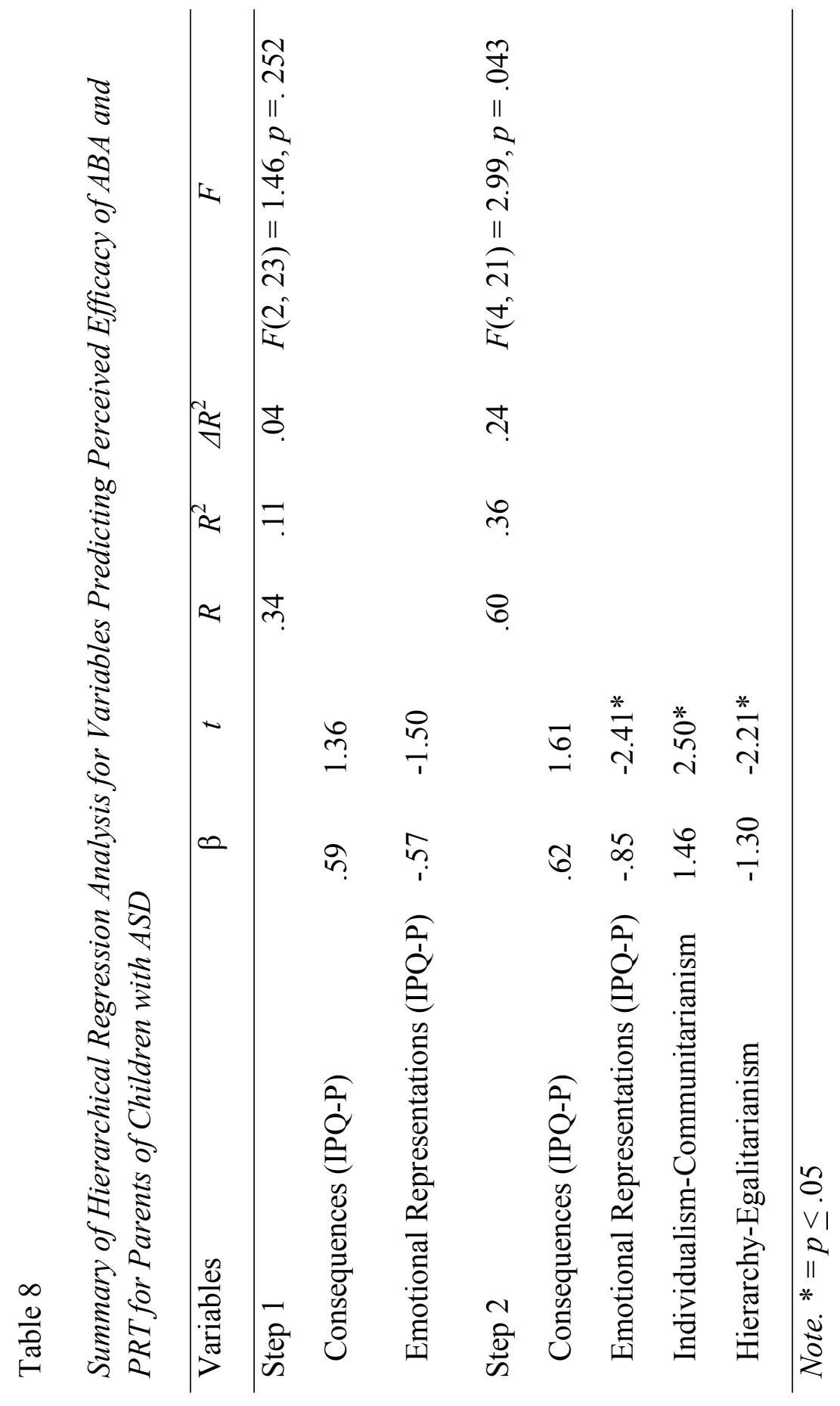




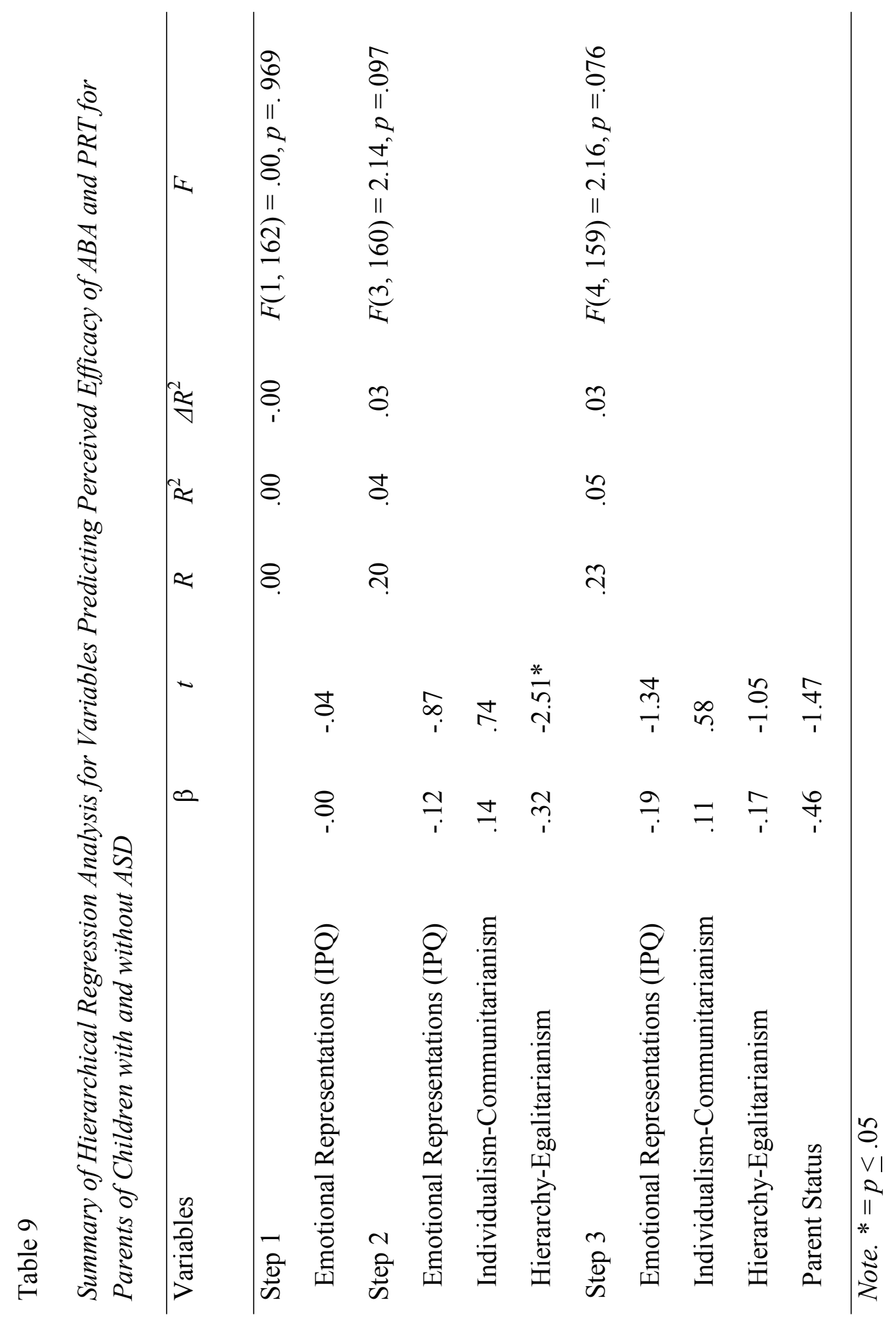




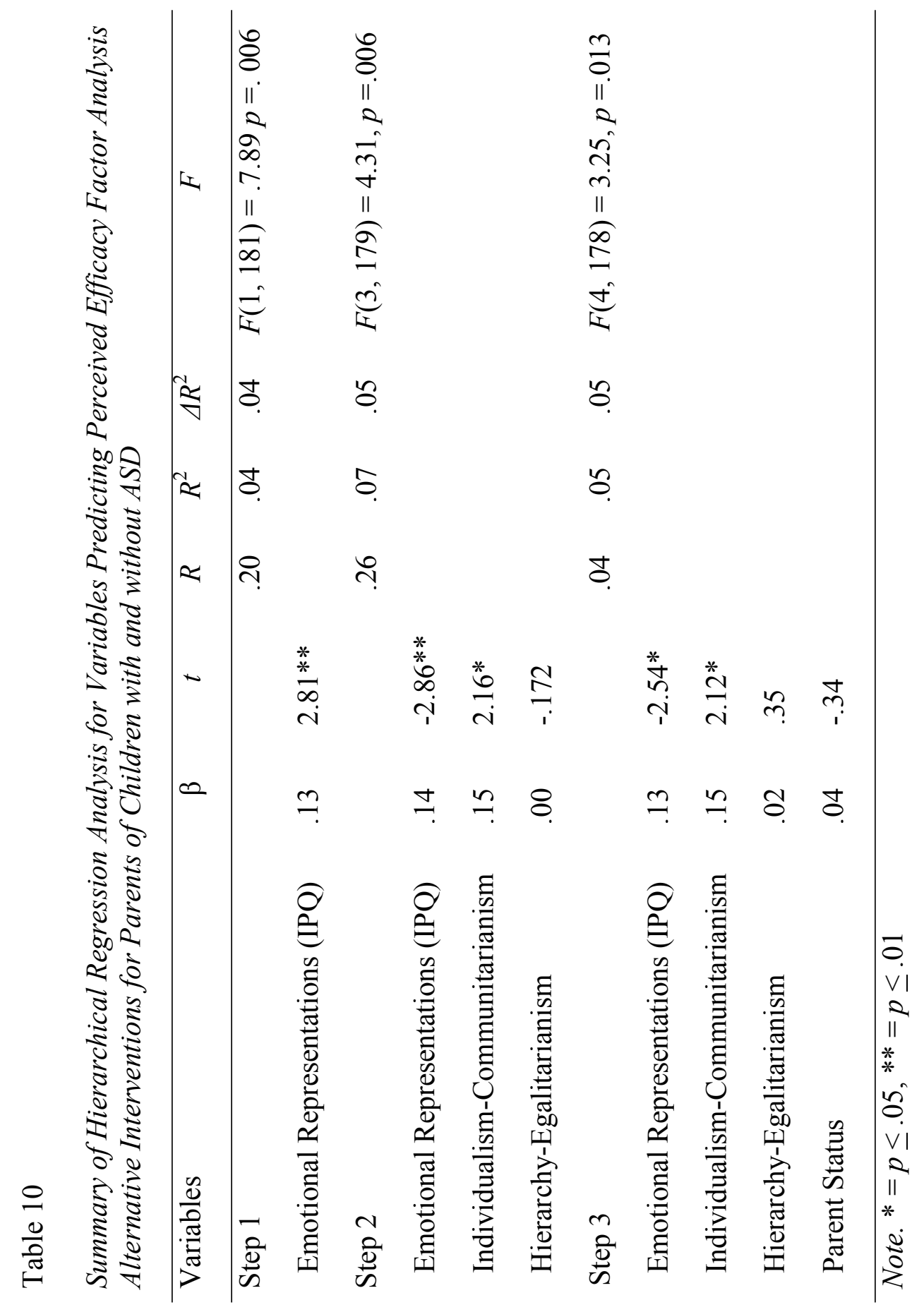




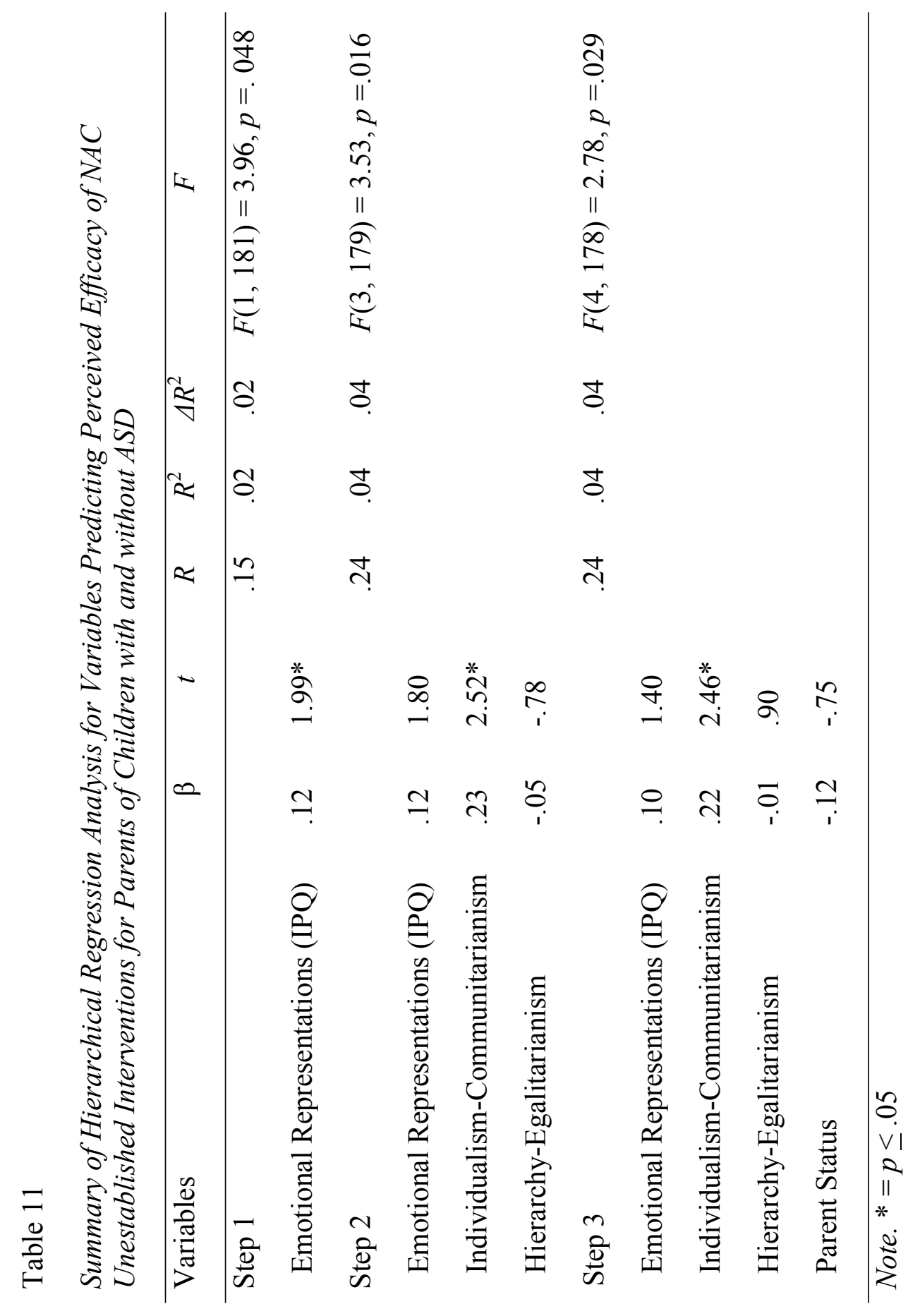

